\title{
Escuela diocesana de Teología para Seglares de Sevilla: historia y documentos (1968-2014)
}

\author{
Diocesan Theology School for laypersons in \\ Seville: History and Documents (1968-2014)
}

\author{
Manuel Martín Riego \\ Prof. Facutad de Teología San Isidoro de Sevilla \\ Director de la Cátedra "Beato Marcelo Spinola" \\ https://orcid.org/0000-0001-5443-4195
}

\begin{abstract}
Resumen: En este artículo de investigación nos acercamos a la Escuela Diocesana de Teología para Seglares (19682014) desde dos aspectos: su historia y la documentación que ha ido generando desde su erección en noviembre de 1968 hasta finales del curso 2013-2014 con su extinción. A través de los documentos, ofrecemos los siguientes aspectos: historia, directores, secretarios, profesorado y alumnado de la Escuela. Desde el archivo analizamos: correspondencia, programas de las asignaturas y seminarios, libros de actas, expedientes académicos, convalidaciones, diplomas, certificados de estudios, asociación de antiguos alumnos "San Telmo". Y por último, los aspectos económicos: libros de cajas y cuentas corrientes, presupuestos, informes y administración. De los documentos del archivo ofrecemos un cuadro de clasificación y el vaciado de las cajas
\end{abstract}

Palabras clave: Teología, seglares, diocesana, profesores, alumnos, asignaturas, seminarios, archivo, documentación.

\begin{abstract}
In this research paper we approach to the Sevillian Diocesan Theology School for Laypersons (1968-2014) from two aspects: its history and documents since its erection in November 1968 until its extinction at the end of 2013-14 academic course. Through documents we offer an analysis of the following: history, directors, secretaries, professors and students. Through archives we analize: letters, academic and seminars programs, books of certificates, validations, diplomas, studies certifications, former students association "San Telmo". Finally, economic aspects as cashbooks and banking accounts, budgets, informs and administration. Based on archival documents we offer a classification .scheme and the settlement of benefits.
\end{abstract}

Keywords: Theology, laypersons, diocesan, professors, students, courses, seminars, archive, documents. 


\section{ESCUELA DIOCESANA DE TEOLOGÍA PARA SEGLARES}

\section{1. Historia}

La Escuela diocesana de Teología para Seglares de Sevilla nació en 1968. Podemos ver, entre las causas decisivas de su nacimiento, las siguientes"

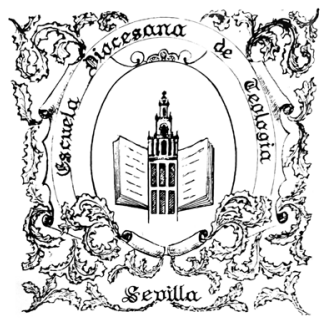

- El impulso renovador del Concilio Vaticano II.

- La importancia del laicado, la porción mayoritaria de la Iglesia y la más necesitada de formación religiosa y teológica.

- La voluntad decidida de un equipo de tres sacerdotes, a su vez profesores: José María Estudillo Carmona, director del enton-

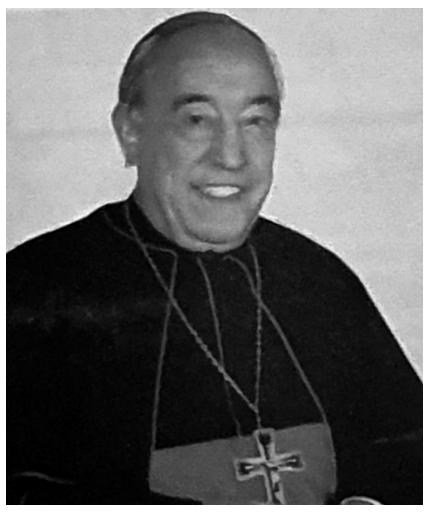

Carenal Bueno Monreal ces llamado "Instituto diocesano de Pastoral", organismo rector y coordinador de las principales tareas pastorales de la archidiócesis de Sevilla de Sevilla, Miguel Oliver Román, director del Secretariado diocesano de Catequesis; Celestino Rivera Aroca, salesiano, iniciador y director del Centro de Estudios Catequéticos de Sevilla.

El 28 de noviembre de 1968 la Iglesia de Sevilla, con el beneplácito del cardenal Bueno Monreal2 ${ }^{2}$, puso en

1 Revista Escuela Diocesana de Teología para Seglares. 25 años al servicio de la Iglesia en Sevilla (1994). Se trata de una revista en conmemoración de los 25 años de la Escuela (1968-69/1993-94), publicada en Sevilla en 1994 para uso privado de los alumnos y profesores de este centro académico y pastoral. De aquí hemos extraído muchas noticias desde el curso 1968-69, primer año de la Escuela, hasta el curso 1993-94 en la celebración de sus bodas de plata.

2 JIMÉNEZ BLASCO, J. El Cardenal José María Bueno Monreal. Un humanista integral. Una biografía (1904-1987) (Sevilla 2016) 73-77; 97-105; 285-334; 567615. El cardenal Bueno Monreal, arzobispo coadjutor de Sevilla en 1954 con derecho a sucesión y administrador apostólico sede plena desde el 29 de octubre de 1955, dio gran impulso a la formación del clero y a los centros teológicos para seglares. Así lo hizo como obispo de Jaca (1946-1950) y de Vitoria (19501954). Aquí erigió la Escuela Superior de Estudios Teológicos y en 1954 afilió los estudios eclesiásticos del seminario conciliar de Vitoria a la Facultad Teológica de la Pontificia Universidad de Salamanca. Como arzobispo de Sevilla construyó 
funcionamiento la Escuela diocesana de Teología para Seglares ${ }^{3}$. Ésta, dependiendo directamente del arzobispado, tuvo como primer director a José María Estudillo Carmona. El Centro de Estudios Cateqéticos (C.E.C.), dependiente de la Congregación salesiana, pero al servicio de toda la Iglesia, tuvo como primeros codirectores a Miguel Oliver Román, sacerdote diocesano, y a Celestino Rivera Aroca, sacerdote salesiano.

Se trata de una Escuela abierta a todos los adultos que deseen conocer a fondo su fe; a los que deseen conjugar su vida cristiana con el momento actual; a quienes tengan cualquier tipo de inquietudes religiosas y a quienes deseen orientar sus vidas al servicio de las personas: jóvenes, padres de familia, educadores y profesores, religiosos y religiosas, militantes de asociaciones cristianas, responsables o animadores de comunidades, responsables de tareas pastorales, etc.

Hemos mencionado anteriormente el nombre de tres sacerdotes como protagonistas en la creación de la Escuela diocesana de Teología para Seglares: nos referimos a José María Estudillo Carmona, Miguel Oliver Román y Celestino Rivera Aroca. De Estudillo Carmona hablaremos en el apartado dedicado a los directores de la Escuela, ya que lo fue desde su creación en 1968 hasta 2007.Y de Miguel Oliver y Celestino Rivera en este momento.

Miguel Oliver Román nació el 12 de enero de 1935 en Los Molares (Sevilla) y realizó la carrera eclesiástica en el seminario menor de Sanlúcar de Barrameda y en el metropolitano de Sevilla. El 19 de marzo de 1961 recibió la ordenación sacerdotal en la catedral de Sevilla

e inauguró el seminaro menor de Pilas en 1961, transformó el seminario metropolitano, ubicado en el palacio de San Telmo, fomentó la salida de los sacerdotes a universidades españolas y extranjeras, erigió el Centro diocesano de Estudios Eclesiásticos Superiores "Isidorianum". Su obra más importante de cara a la formación el clero fue el Centro de Estudios Teológicos de Sevilla en 1969, hoy Facultad de Teología San Isidoro de Sevilla. Anteriormente, en 1968 había creado la Escuela diocesana de Teología para Seglares y en 1957 la Escuela de Magisterio de la Iglesia "Cardenal Spínola", a cargo de las Esclavas del Divino Corazón.

3 Por más que hemos buscado el decreto de erección de la Escuela diocesana de Teología para Seglares en el Boletín Oficial del Arzobispado de Sevilla, no lo hemos encontrado. Entendemos que, al ser un fruto del Instituto diocesano de Pastoral, no lo necesitaría. Por otra parte, la Escuela diocesana de Teología para Seglares no tuvo sello propio en los primeros años, usando en los libros de actas el del Instituto de Orientación Pastoral, cuyo director era José María Estudillo Carmona, primer director de dicha Escuela diocesana de Teología para Seglares. 


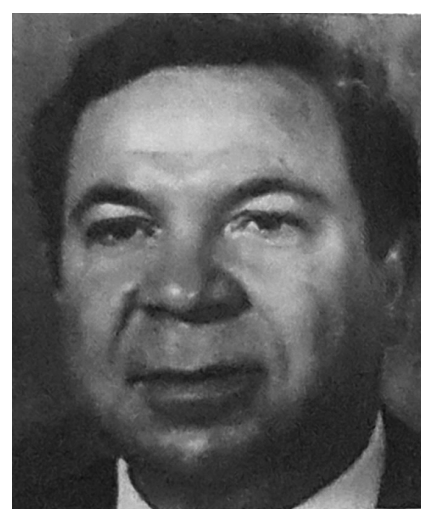

Miguel Oliver Román

de manos del cardenal Bueno Monreal ${ }^{4}$. Entre sus títulos enumeramos los siguientes: diplomado en teología pastoral en la Pontificia Universidad Lateranense de Roma (1962), diplomado en sociología pastoral en el Centrum Internationale pro Sociale Institutione Cleri de Roma (1963), diplomado en catequesis y pastoral en el Lumen Vitae de Bruselas (1964), licenciado en sagrada escritura por el Pontificio Instituto Bíblico de Roma (1973) y doctor en teología por la Pontificia Universidad Urbaniana de Roma (1975).

Entre sus cargos, antes de ser nombrado rector del Centro de Estudios Teológicos de Sevilla, figuran los siguientes: director del secretariado diocesano de catequesis de Sevilla (7 años); director de la hoja informativa diocesana parroquial de Sevilla (5 años); miembro del equipo nacional de catequesis para los cursos de verano para la formación religiosa del profesorado; profesor de cursos de verano organizados por el secretarido nacional de catequesis; párroco de la Resurrección del Señor de Sevilla; fundador y organizador de las"semanas bíblicas andaluzas"; fundador de las Escuelas de Teología para Seglares de Sevilla y Jerez de la Frontera, de la Escuela de Catequistas de Sevilla y del secretariado de catequesis de Jerez de la Frontera; profesor del seminario conciliar de Sevilla, del Centro de Estudios Teológicos y de la Escuela diocesana de Teología para Seglares de Sevilla. Es nombrado rector del Centro de Estudios Teológicos (C.E.T.) en 1981, cargo en el que permanecerá hasta octubre de 1990. Cuenta con numerosas publicaciones entre libros y artículos en revistas de investigación. Desde 2002 es canónigo de la catedral de Sevilla, actualmente emérito.

Celestino Rivera Aroca nació en Madrid el 19 de septiembre de 1930, hijo mayor de una familia de siete hermanos. Tras la guerra civil española, sus padres se trasladaron a Sevilla, pues el padre

4 Fondo documental del Centro de Estudios Teológicos de Sevilla. Sección: Curriculum de Profesores; MARTín RIEGO, M. "La formación del clero de Sevilla: Seminario (1831-1931), Pontificia Universidad (1897-1931) y Centro de Estudios Teológicos de Sevilla (1969)", en Anuario de Historia de la Iglesia Andaluza. Vol. XIII (2020) 82-91; 98. 
pertenecía al cuerpo militar ${ }^{5}$. Comenzó sus estudios primarios en el colegio salesiano de San Benito, calle Calatrava 34, pasando luego a estrenar el colegio salesiano de San Pedro en Triana. En 1943 marchó como aspirante salesiano a Antequera y Montilla, haciendo su noviciado en San José del Valle (1947-48) y su primera profesión religiosa en 1948. Terminados los primeros estudios de filosofía en Consolación de Utrera, fue destinado a San José del Valle (1950-52) como profesor y asistente de novicios. En

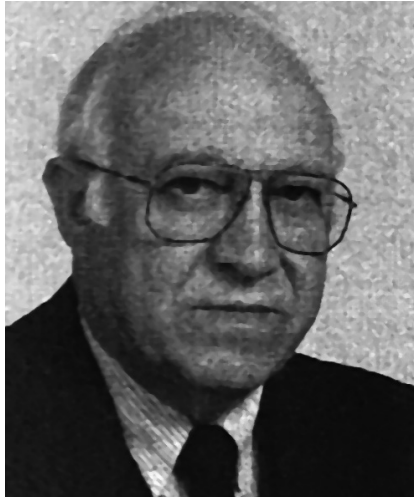

Celestino Rivera Aroca 1952 amplió sus estudios filosóficos en el Pontificio Ateneo Salesiano de Turín, obteniendo la licenciatura en filosofía en 1955. En el mismo Ateneo realizó los estudios teológicos, culminándolos con la licenciatura en teología (1960). El 11 de febrero de 1960 recibió la ordenación sacerdotal en la basílica de María Auxiliadora de Turín.

En 1960 fue destinado como formador de los jóvenes filósofos en San José del Valle (1960-1964), pasando como profesor de teología al teologado salesiano de Sanlúcar la Mayor. Enviado a París, obtuvo la licenciatura en estudios catequéticos en 1967. En el curso 1967-68 volvió a San José del Valle como profesor de los salesianos estudiantes de filosofía. En 1968 fue destinado a la casa inspectorial de Sevilla, donde residió hasta 1978, desempeñando varios cargos: consiliario inspectorial de antiguos alumnos salesianos (1968-70), vicario inspectorial (1972-73), fundador y director del Centro de Estudios Catequéticos (C.E.C.). En esta época, durante varios cursos académicos, fue profesor de catequética en el Centro de Estudios Teológicos de Sevilla.

Desde 1971 a 1978 desempeñó el cargo de vicario de enseñanza en la archidiócesis de Sevilla con el cardenal Bueno Monreal. Desde este cargo ocupó un papel relevante en la formación de los profesores de religión y en a la recién creada Escuela diocesana de Magisterio

Los datos del curriculum de Celestino Rivera Aroca, profesor y amigo del que escribe estas páginas, nos han sido facilitados por Rosendo AlabauVila, secretario provincial de la inspectoría de María Auxiliadora de la Congregación salesiana. Desde estas páginas nuestro público agradecimiento por su amabilidad y generosidad. 
Cardenal Spínola, fusión en 1972 de la tres Escuelas de Magisterio de la Iglesia: Cardenal Spínola ${ }^{6}$ (Esclavas del Divino Corazón), Santa $\mathrm{Ana}^{7}$ (Hermanas de la Caridad de Santa Ana) y la de San Rafael ${ }^{8}$ (Congregación salesiana), de la que Celestino había sido profesor y director . Según los datos obtenidos en las entrevistas con la hermana Pilar Sánchez, primera directora de la Escuela diocesana de Magisterio Cardenal Spínola9 , la figura de Celestino Rivera fue clave en dicha fusión, desde su cargo de vicario de enseñanza de la archidiócesis hispalense. También ejerció como secretario técnico de enseñanza de los obispos del Sur de España.

De 1978 a 1982 residió en la casa generalicia de Roma, trabajando en el Dicasterio de Pastoral Juvenil. Entre 1982 y 1988 ejerció el cargo de provincial de la inspectoría de Sevilla (Andalucía Occidental y Extremadura). Desde este servicio, además de sus tareas de gobierno de cara a la Congregación salesiana, busca cauces para la formación de seglares comprometidos con la Iglesia y la sociedad, incidiendo, sobre todo, en el mundo de la enseñanza y en la formación de adultos. De 1988 a 1990 ejerce como párroco en la parroquia de San Juan Bosco de Triana. En 1990 es destinado a la Casa Don Bosco de Madrid como delegado nacional de los antiguos alumnos salesianos. Intervenido quirúrgicamente en 1993, continuó en su comunidad madrileña. El 11 de octubre de 1994 fue ingresado en el hospital de San Juan de Dios de Sevilla, donde falleció el 6 de noviembre de 1994. Había cumplido 64 años de edad, 46 de profesión salesiana y 34 de sacerdocio. Las exequias se celebraron al día siguiente en el santuario de María Auxiliadora de Sevilla.

6 MÁRQUEZ DE LA PLATA, J. M.-MARTíN RIEGO, M., “Historia de la Escuela de Magisterio "Cardenal Spínola" de Sevilla", en Marcelo Spínola. Estudios de un Centenario (1906-2006) (Sevilla 2006) 203-306.

7 HOLGADO BARROSO, J.-MÁRQUEZ DE LA PLATA, J. M.-MARTÍN RIEGO, M., "Escuela de Magisterio de "Santa Ana"de Sevilla (1962-1972)", en Isidorianum, n. 39 (2011) 223-276.

8 HOLGADO BARROSO, J.-MARTÍN RIEGO, M., "Escuela de Magisterio de“San Rafael" de los Salesianos: San José del Valle (Cádiz (1961-1968) y Sevilla (19681972)", en Anuario de Historia de la Iglesia Andaluza. Vol. IV (2011) 229-272.

9 HOLGADO BARROSO, J.-MÁRQUEZ DE LA PLATA, J. M.- MARTÍN RIEGO, M., De la Escuela de Magisterio de la Iglesia al C.E.S. Cardenal Spinola CEU (19572011) Historia de una institución (Sevilla 2013) 219-252. 


\subsubsection{Primer curso: $1968-69$}

La Escuela de Teología para Seglares comenzó su primer curso académico el 28 de noviembre de 1968. De este primer curso, 1968-1969, destacamos los siguientes datos:

- Número de profesores: 9

- Número de alumnos: 75.

- Días de clases: jueves y sábados de 19 a 21,30 horas. Son tres clases diarias.

- Lugar: Colegio mayor San Juan Bosco.

- Materias impartidas: antiguo testamento, nuevo testamento, el Dios de la revelación, revelación y tradición, cristología, mariología, el hombre nuevo, liturgia, eucaristía y fenomenología religiosa.

- Secretaría: Instituto diocesano de Pastoral, archidiócesis de Sevilla.

\subsubsection{Primer decenio}

La Escuela diocesana de Teología para Seglares, durante los diez primeros años, funcionó ofreciendo solamente dos cursos: primero y segundo con 9 asignaturas cada curso. Diversas en tratamiento, según la importancia cualitativa de las mismas. Durante el curso académico 1970-71 los días de clases fueron miércoles y viernes para los alumnos de primer curso, jueves y sábados para los del segundo. El horario era de 19 a 21,30 horas con clases de 45 minutos de duración. Durante los cursos académicos 1969, 1970 y 1971 las clases se impartían en el colegio salesiano de la Santísima Trinidad de Sevilla o en el colegio mayor San Juan Bosco.

A partir del curso 1971-72, la Escuela se ubicó en el edificio del seminario metropolitano de Sevilla, en el palacio de San Telmo. En dicho curso los profesores eran las siguientes personas: Jesús Borrego, Antonio Brajones, Luis Briones, Diego Capado, José María Delgado, Francisco Díaz Rodríguez, Miguel Ángel Díez de Palencia, José María Estudillo, Antonio García del Moral, José María Garrido, Juan Garrido Mesa, Francisco Gil Delgado, Antonio González Dorado, Juan Guillén Torralba, Antonio Ismael García, José Morales Carmona, Manuel del Trigo Campos y Valentín Vigueras.

En el palacio de San Telmo estuvo ubicada la Escuela diocesana de Teología para Seglares desde el curso 1971-72 al curso 1998-99. Primero en el mismo palacio y posteriormente en unas instalaciones 
prefabricadas (llamadas "caracolas") en el jardín del palacio. En el curso 1999-2000 la Escuela se trasladó a la zona académica del nuevo edificio del seminario metropolitano Nuestra Señora del Buen Aire y San Isidoro de Sevilla, situado en la avenida Cardenal Bueno Monreal, 43, donde sigue hasta el día de hoy.

El plan de estudios se fue ampliando. En los siguientes cursos académicos, tenemos las siguientes asignaturas. En el curso primero: fenomenología de la religión e historia de las religiones, antiguo testamento (primera parte), nuevo testamento (introducción), el Dios de la revelación, cristología, mariología, revelación y tradición, tratado de la gracia, liturgia y eucaristía. Y en el curso segundo: fenomenología de la religión, antiguo testamento (segunda parte), nuevo testamento, eclesiología, teología sacramental, teología moral, doctrina social de la Iglesia, y escatología.

Entre los cursos 1973-74 y 1975-76 destacan los dos siguientes hechos: un considerable aumento de los alumnos matriculados, sobrepasando el centenar en primero, y el acceso de un número cada vez mayor de seglares.

\subsubsection{Crecimiento de la Escuela e integración en el Centro de Estudios Teológicos (C.E.T.)}

A partir del curso 1979-1980, a petición del alumnado, el curriculum académico se amplía un tercero. Se trataba no tanto de multiplicar el número de materias y asignaturas, cuanto de concederles mayor tiempo de atención y profundización. Y, a partir del curso 1986-87, se incrementó hasta un total de cuatro cursos académicos obligatorios para la obtención del diploma. Con esta nueva planificación se intentaba completar lo mejor posible la formación teológica y la síntesis humano-cristiana de su alumnado.

En la reunión de la junta de patronos del 29 de marzo de 1980 se trató de una mayor vinculación de la Escuela de Teología al CET, ya que el número de alumnos se elevaba a más de $200^{10}$.

En 1985, la Escuela diocesana de Teología para Seglares, con fecha 26 de septiembre de 1985, solicitó a la junta de patronos del Centro de Estudios Teológicos y a su director Miguel Oliver Román su integración

10 Fondo documental del Centro de Estudios Teológicos. Sección I: Gobierno-Junta de Patronos, caja n. 1. Reunión del 29 de marzo de 1985. 
en esta institución académica. Era una integración relativa al profesorado y al uso de las instalacioes, , manteniendo su identidad diocesana y su autonomía en la dirección, organización y economía. En estos aspectos siempre dependió de la archidiócesis de Sevilla.

La Escuela de Teología ${ }^{11}$, en colaboración del Centro de Estudios Teológicos, actúa según las exigencias que la Comisión Episcopal de Enseñanza, como la jerarquía diocesana, ha establecido tanto en conformidad con las directrices para la actualización y formación permanente del profesorado de religión y moral católica en vistas a cubrir las materias del sector teológico para la obtención de la declaración eclesiástica de idoneidad (D.E.I), requisito imprescindible para impartir la formación religiosa en los centros docentes.

De un díptico de la Escuela, publicado para al curso 1985-86, podemos extraer que la Escuela diocesana de Teología para Seglares ${ }^{12}$,

\section{Es:}

Un lugar de servicio de la formación humana y cristiana, que la Iglesia de Sevilla brinda a toda clase de seglares adultos sin distinción.

\section{Intenta:}

Con sus actividades educativas, colaborar en lo posible, en la transformación rápida y esperanzadora que se está produciendo en todos los pueblos e iglesias en España.

\section{Está abierta:}

- a los adultos que deseen poner al día su fe y creencias.

- a quienes quieran conjugar su vida cristiana y el momento actual.

- a quienes tengan inquietudes religiosas, deseos de mayor compromiso.

- a quienes deseen orientar su vida y tareas al servicio de los demás.

\section{Interesa:}

- a los jóvenes.

- a toda clase de educadores: padres, profesores de EGB, BUP y FP.

- a responsables e iniciadores de grupos y comunidades cristianas: populares, parroquiales, religiosas, etc.

- a los cristianos que deseen iluminar, desde el Evangelio, sus actividades socio-políticas y laborales.

11 Fondo documental de las Escuela diocesana de Teología para Seglares. Sección II: Gestión Académica y Organización de la Docencia- Seminarios, caja n. 4.

12 Fondo documental de las Escuela diocesana de Teología para Seglares. Sección I: Gobierno-Correspondencia, caja n. 1. 


\subsubsection{La Escuela desde 1986-87 al curso 2006-07}

En el curso 1993-94, con motivo de la celebración de los 25 años, la propia Escuela publicó una revista de 36 páginas, titulada Escuela Diocesana de Teología para Seglares. 25 años al servicio de la Iglesia en Sevilla. De ella hemos extraído la mayor parte de los datos ofrecidos en esta breve historia de la misma ${ }^{13}$.

En el curso 1986-87, como hemos indicado en el apartado anterior, el curriculum académico se amplió a cuatro cursos institucionales, lo que supone un total de 700 horas lectivas. Dicho curriculum fue demandado por los alumnos y refrendado por el claustro de profesores. En el primer curso se impartían las siguientes asignaturas: teología fundamental, introducción al antiguo testamento, pentateuco y libros históricos, misterio de Dios, introducción al nuevo testamento e introducción a la celebración cristiana (liturgia). En el curso segundo: fe y compromiso cristiano, historia de la Iglesia antigua y medieval, doctrina social de la Iglesia, sacramento del orden sacerdotal, sacramento del matrimonio, el evangelio de Jesús y sacramentos de la iniciación cristiana. En el curso tercero: la Iglesia en el mundo (eclesiología), teología moral fundamental, cristología, fenomenología religiosa de las grandes religiones. Y en el curso cuarto: libros proféticos, Hechos de los Apóstoles y San Pablo, historia de la Iglesia moderna y contemporánea, sacramento de la penitencia, sacramento de la unción de enfermos, los seglares y su misión en la Iglesia y la plenitud de los tiempos (escatología).

A partir del curso 1990/91, durante los meses de enero y febrero, la Escuela ofrecía cursos de actualización para los alumnos que habían terminado los cuatro cursos institucionales. Entre las distintas temáticas, tenemos las siguientes: religiosidad popular (1991); el Verbo encarnado (1992); las bienaventuranzas (1993); mariología (1994); reinado de Dios (1994); oración y liberación (1995); hombre nuevo. Mandamiento nuevo (1996); cristología (1997); Espíritu Santo: señor y dador de vida (1998); Dios Padre (1999); la salvación en el 2000. Año jubilar (2000); la dimensión existencial del cristiano (2001); la salvación de Dios es universal (2002); comunidad humana. Comunidad cristiana (2003); resurrección: plenitud de la vida tras la muerte (2004); grandes retos actuales: propuesta cristiana (2005); la

13 Revista Escuela Diocesana de Teología para Seglares. 25 años al servicio de la Iglesia en Sevilla (1994) 9-33. 
Biblia: el libro de la familia y la comunidad (2006) ${ }^{14}$.

El curso académico 199394 comenzó el 19 de octubre de 1993 con un total de 383 alumnos (el 25\% lo eran de asignaturas sueltas). De estos 383 matriculados, 128 eran varones y 255 mujeres (45 pertenecían a distintas instituciones religiosas). Durante dicho curso, además de la clases, se celebraron varias eucaristías en los momentos litúrgicos más importantes (inauguración de curso, adviento, navidad, cuaresma, pascua y final de curso). En el curso 1993-94 se celebró

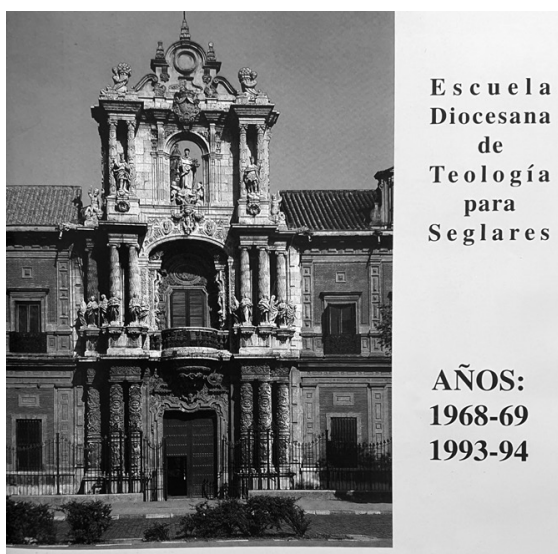
el 25 aniversario de la erección

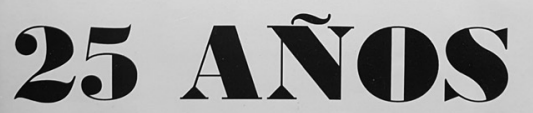

AL SERVICIO

DE LA IGLESIA EN SEVILLA

de la Escuela. Se presentó, como ya hemos indicado, la Revista Escuela Diocesana de Teología para Seglares. 25 años al servicio de la Iglesia en Sevilla.

Este acontecimiento contó con varios actos: semana teológica y acción de gracias (23-26 de noviembre de 1993), velada cultural y presentación de la revista, y por último, una jornada-convivencia de antiguos alumnos. La formación se completó con dos conferencias: una, la teología al servicio de la evangelización, por Antonio González Dorado, rector de la Facultad de Teología de Granada, y la otra, los seglares al servicio de la justicia y de la paz, por Pablo Martín Calderón, secretario nacional de Cáritas ${ }^{15}$.

En el curso 1995-96 figuran 23 profesores, todos ellos con una excepcional experiencia. La casi totalidad de los mismos son profesores del Centro de Estudios Teológicos y de congregaciones religiosas, impartiendo las mismas materias en las que eran especialistas, bien como doctores o licenciados. La mayor parte de los profesores son

14 Fondo documental del Instituto Superior de Ciencias Religiosas San Isidoro y San Leandro. Memoria de la Escuela Diocesana de Teología para Seglares. Curso 2011-2012 (Sevilla, septiembre 2012). Se trata de un documento para uso interno.

15 Revista Escuela Diocesana de Teología para Seglares. 25 años al servicio de la Iglesia en Sevilla (1994) 20. 
sacerdotes diocesanos o religiosos, figurando pocos seglares. Por otra parte, la Escuela garantiza la seriedad en todas la enseñanza de sus materias, tanto en sus contenidos esenciales, cuanto en el número de horas de clases y de trabajos. La casi totalidad de estos profesores están implicados en la acción pastoral de la Iglesia e intentan acercar sus conocimientos a los alumnos para que se comprometan en el servicio a la sociedad y, de una forma especial, a los más vulnerables ${ }^{16}$.

Tenemos el elenco de profesores que impartieron algunos cursos de actualización teológica. En enero y febrero de 2008 se celebró un ciclo de conferencias con el título "familia, educación y vivencia cristiana", dirigido a la actualización teológica de los antiguos alumnos y de los seglares que quisieran profundizar en la fe. Se estudió la familia desde las siguientes perspectivas: bíblica, antropológica, ética, teológica, pastoral y canónica con los siguientes ponentes: Gonzalo Flor Serrano, Manuel Mallofret Lancha, José María Garrido Luceño, Francisco Javier Fernández de Liencres, Mariano Pérez de Ayala Conradi, Antonio María Calero de los Ríos y Teodoro León Muñoz ${ }^{17}$. Todos eran profesores de la Escuela y algunos de ellos desde sus primeros años de andadura. En los siguientes cursos académicos se ofrecieron seminarios de patrología, mariología, salmos, eucaristía y cartas paulinas. Todas estas materias se ofertaban las tardes de los jueves.

En el curso 2008-09, durante los meses de enero y febrero de 2009, se impartió un ciclo de conferencias sobre el Concilio Vaticano II con las siguientes ponencias y conferenciantes: génesis, contexto histórico y teológico del Vaticano II (Antonio Calero de los Ríos), la reforma de la liturgia (Luis Rueda Gómez), la Iglesia Pueblo de Dios (José María Garrido Luceño), diálogo de la Iglesia con el mundo (Mariano Pérez de Ayala Conradi), la Palabra de Dios, fuente de la vida del cristiano y de la Iglesia (Gonzalo Flor Serrano), balance del Vaticano II tras los 40 años de su clausura (Antonio Calero de los Ríos). Por último, se ofreció una conferencia sobre el Sínodo de Sevilla de 1973, fruto de la recepción y puesta en práctica delVaticano

\footnotetext{
16 Fondo documental de la Escuela diocesana de Teología para Seglares. Sección III: Administración-Libros de ingresos y gastos, caja n. 1.

17 Fondo documental de la Escuela diocesana de Teología para Seglares. Sección II: Gestión Académica y Organización de la Docencia-Seminarios, caja n. 4.
} 
II en la diócesis de Sevilla, por Antonio Hiraldo Velasco, secretario general del Sínodo y párroco de San Román de Sevilla ${ }^{18}$.

\subsubsection{La Escuela desde 2007-08 al 2013-14}

En 2008 el cardenal de Sevilla, Carlos Amigo Vallejo, encargó a Antonio Bueno Ávila, director de la Escuela diocesana de Teología para Seglares desde junio de 2007, que pusiera en su horizonte la creación de un Instituto Superior de Ciencias Religiosas. Para dicho fin, se elige el patrocinio de la Facultad de Teología de la Pontificia Universidad de Salamanca. No se pudo realizar dicha vinculación, ya que la Congregación para la Educación Católica no permitía la erección de ningún nuevo Instituto hasta que no se publicase la nueva Instrucción sobre los Institutos Superiores de Ciencias Religiosas. Dicha Instucción tenía como finalidad mejorar la calidad académica de los Institutos ya existentes y establecer los nuevos criterios para la erección de los nuevos.

Publicada la Instrucción el 28 de junio de 2008 y pudiéndose retomar el proceso de creación del Instituto, el nuevo arzobispo de Sevilla, Juan José Asenjo Pelegrina, piensa que es más oportuno que el Instituto esté vinculado a la Facultad de Teología San Dámaso. Presentada toda la documentación requerida y cumpliendo todos los requisitos de la Instrucción, la Congregación para la Educación Católica eligió la fecha de 13 de noviembre de 2011, festividad de San Leandro, para la firma del decreto de erección del Instituto Superior de Ciencias Religiosas "San Isidoro y San Leandro", por un periodo de cinco años. También indicaba la obligación, en el tercer año, de enviar a la citada Congregación un informe detallado de toda la vida académica y docente del Instituto con vista a su continuidad ${ }^{19}$. Con dicho decreto se culminaba todo un proceso que se inició el 1 de abril de 2011 con la solicitud dirigida por Juan José Asenjo Pelegrina, arzobispo de Sevilla, al cardenal Antonio María Rouco Varela, arzobispo de Madrid y gran canciller de la Universidad Eclesiástica San Dámaso, donde le expresaba su deseo de crear un Instituto Superior de

18 Fondo documental de la Escuela diocesana de Teología para Seglares. Sección II: Gestión Académica y Organización de la Docencia-Seminarios, caja n. 4.

19 Fondo documental del Instituto Superior de Ciencias Religiosas, Memoria Curso 2011-2012 (Sevilla, septiembre 2012). Se trata de un documento para uso interno. 
Ciencias Religiosas afiliado a su Facultad de Teología. La Conferencia Espiscopal Española concedió su placet el 22 de junio de 2011.

Con esta meta, el director y los dos secretarios (Antonio González Álvarez y Rocío González León) trabajaron, durante este trienio, orientando sus esfuerzos en dar al nuevo Instituto una base y una estructura sólida. Fueron años de duro trabajo donde se ponen en marcha los órganos de gobierno del Instituto, es decir, el claustro de profesores y el consejo del Instituto, se crea también la imagen corporativa del Instituto y el reglamento de régimen interno que será aprobado definitivamente años después por la comisión permanente de la Facultad de Teología de la Universidad Eclesiástica San Dámaso el 22 de marzo de 2018. Asimismo, se crea toda la infraestructura necesaria para que la labor docente, académica y administrativa del Instituto se pudiese desarrollar de manera conveniente.

Pasados los tres años y, a través de la Universidad Eclesiástica San Dámaso, el 4 de diciembre de 2014 se envía, en tiempo y forma, el informe solicitado por la Congregación para la Educación Católica que, a través de una carta con fecha del 7 de enero de 2015 y dirigida al gran canciller de la Universidad Eclesiástica San Dámaso, comunica la continuidad del Instituto. El 3 de agosto de 2016, concluido el primer quinquenio, se renueva el decreto de erección por otros cinco años.

Durante cuatro años, del 2011 al 2014, conviven la Escuela diocesana de Teología para Seglares y el Instituto Superior de Ciencias Religiosas, ya que tanto la extinción de la primera como la creación del segundo se realizaron de manera progresiva. De este modo, se fueron implantando uno a uno y en cada año académico los cursos del Instituto, al mismo tiempo que se les dio a los alumnos de la Escuela diocesana de Teología la posibilidad de finalizar sus estudios para la obtención del diploma. Durante este periodo de transición, todos los trabajos de dirección y secretaría buscaron siempre la continuidad de ambas instituciones, desde el necesario salto de calidad académica que suponía la creación del Instituto. De hecho, hubo alumnos de la Escuela diocesana de Teología para Seglares que pasaron al Instituto, donde felizmente algunos de ellos obtuvieron sus títulos de bachillerato y licenciatura en Ciencias 
Religiosas. Tales son los casos de César Mateos Cordero $^{20}$ y de Juan Navarro González ${ }^{21}$, por citar algunos.

En los cursos 2008-09 y 2009-10 la Escuela trabajó en la organización de varios seminarios con profesores de la Escuela y con nuevos sacerdotes diocesanos que habían concluido sus estudios de doctorado o licenciatura en distintas universidades eclesiásticas de Roma. De esta manera, se ampliaba la oferta formativa. En el curso 2008-09, como ya hemos comentado anteriormente, se impartieron los seminarios de patrología, concilio Vaticano II y mariología y en el 2009-10 los seminarios de salmos, eucaristía y cartas paulinas.

\section{DIRECTORES}

\section{1. José María Estudillo Camona (1968-2007)}

Nació en Carmona (Sevilla) el 24 de noviembre de $1931^{22}$. Después de sus estudios primarios, ingresó en el seminario menor de Sanlúcar de Barrameda para cursar los de humanidades. En 1946 pasó al seminario metropolitano de Sevilla, ubicado en el palacio de San Telmo, donde estudió la filosofía

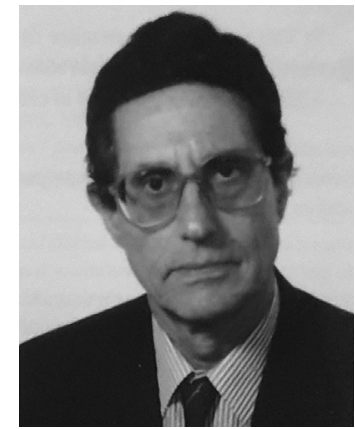

José $\mathrm{M}^{\mathrm{a}}$ Estudillo Carmona

20 Fondo documental de la Escuela diocesana de Teología para Seglares. Sección II: Gestión Académica y Organización de la Docencia-Expedientes Académicos, caja n. 6. César Mateos Cordero se matriculó en la Escuela diocesana de Teología para Seglares en primero en el curso académico 2010/11, obteniendo unas excelentes calificaciones. Al año siguiente, creado ya el Instituto Superior de Ciencias Religiosas San Isidoro y San Leandro, pasó su matrícula a éste, donde obtuvo su licenciatura. Fue el primer licenciado del Instituto. Según nuestro amigo César Mateos, fue "un camino largo, pero apasionante y fructífero".

21 Fondo documental de la Escuela diocesana de Teología para Seglares. Sección II: Gestión Académica y Organización de la Docencia-Expedientes Académicos, caja n. 6 (N/Q). Juan Navarro, natural de Utrera, cursó los cuatro años de teología en la Escuela diocesana, finalizando en 2008. Posteriormente, se matriculó en varios seminarios de teología y asignaturas de reciclaje. Creado el Instituto, se matriculó en asignaturas sueltas en este centro académico.

22 Fondo documental del Centro de Estudios Teológicos de Sevilla. Sección: Curriculum de Profesores. 
y parte de la teología, finalizándola en la Pontificia Universidad de Comillas (Madrid), donde obtuvo la licenciatura en teología en 1958. Recibió la ordenación sacerdotal en la catedral de Sevilla el 6 de abril de 1957. Su primer destino fue la parroquia del Dulce Nombre de Jesús de Algámitas (Sevilla), arciprestazgo de Morón de la Frontera. En Algámitas ejerció como párroco desde 1958 a 1960. De 1960 a 1966 fue coadjutor de la parroquia de San Roque de Sevilla, a la vez que cursaba la carrera de filología moderna en la Universidad de Sevilla, donde obtuvo la licenciatura en 1966. En 1981-82, gozó de un año sabático en Roma, donde recibió un curso de actualización teológica por profesores de la Gregoriana, y obtuvo la diplomatura en arqueología paleocristiana en el Pontificio Instituto de Arqueología, sito en la via Napoleone III de Roma. En 1985 realizó el curso de"métodos cualitativos de enseñanza e investigación" del I.C.E. en Sevilla.

Entre sus cargos relacionados con la educación y enseñanza figuran los siguientes: auxiliar de la cátedra de literatura de la facultad de filosofía y letras de Sevilla y auxiliar de la cátedra de historia y literatura italiana de dicha facultad; primer director de la Escuela diocesana de Teología para Seglares de Sevilla (1968 al 4 de junio de 2007); profesor de dicha Escuela (1968-2014), del seminario metropolitano San Isidoro y San Francisco Javier de Sevilla (1960-1969), del Centro de Estudios Catequéticos de los salesianos, del Centro de Estudios Teológicos de Sevilla (1969-2009) y director del departamento de pastoral del mismo (1982-1990). Entre las asignaturas impartidas en el Centro de Estudios Teológicos y en la Escuela diocesana de Teología para Seglares figuran las siguientes: fenomenología de la religión, historia de la salvación en las grandes religiones y teología pastoral fundamental. También dos seminarios: religiosidad popular (1982-85) y pastoral de la comunidad cristiana (1982-85). Por último, mencionamos sus años de profesor de la Escuela diocesana de Magisterio“Cardenal Spínola” (1971-1998) y jefe de departamento: lengua y literatura española (1975-1981) e idiomas modernos (1983-1998).

Entre sus cargos diocesanos, además los anteriores, mencionamos los siguientes: consiliario diocesano de la JOC (1961-64); secretario de la comisión preparatoria del Sínodo Hispalense, miembro del departamento de adultos del secretariado diocesano de catequesis de Sevilla; director del Instituto diocesano de Pastoral (1965-1977); presidente de la comisión diocesana del diaconado permanente y los 
ministerios laicales (1989-1996); director del instituto de orientación pastoral de Sevilla; secretario de la delegación diocesana del clero. Fue durante muchos años capellán de las Adoratrices del Santísimo Sacramento de Sevilla, de las monjas cistercienses del monasterio de San Clemente de Sevilla y, finalmente, del hospital de San Juan de Dios de Sevilla, donde vivió los últimos años de su vida. Falleció en Sevilla el 10 de abril de 2019, a los 87 años de edad ${ }^{23}$.

\section{2. Antonio Bueno Ávila (2007-2014)}

Desde junio de 2007 el director de la Escuela es el doctor Antonio Bueno Ávila, sacerdote diocesano $^{24}$. Nacido en Sevilla el 31 de marzo de 1973, cursó la EGB en la Academia Politécnica Sevilla y Bachillerato y COU en el Instituto de Bachillerato Triana. Tras aprobar la selectividad, en 1991 comenzó sus estudios en la Universidad de Sevilla, obteniendo la licenciatura en geografía e historia, con la especialidad en historia del arte en 1996. Terminados los estudios universitarios, ingresó en el seminario metropolitano Nuestra Señora del Buen Aire y

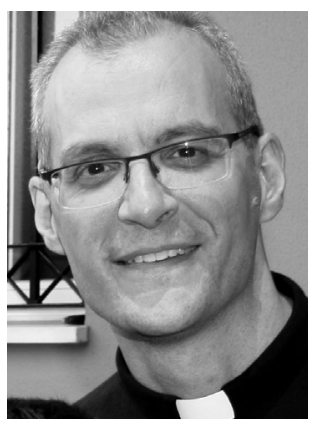

Antonio Bueno Ávila San Isidoro de Sevilla, obteniendo el grado de bachiller en teología en 2002 en el Centro de Estudios Teológicos de Sevilla, con una síntesis teológica titulata "la historia, dimensión estructurante del misterio cristiano" 25 . El 15 de septiembre de 2002 fue ordenado sacerdote en la catedral de Sevilla. Desde 2002 a 2007 estudió en el Instituto Patrístico Augustinianum, obteniendo el grado de doctor en teología y ciencias patrísticas el 24 de mayo de 2007 con la tesis “De su plenitud todos hemos recibido gracias tras gracia... Exégesis patrística

23 BOLETÍN OFICIAL DEL ARZOBISPADO DE SEVILLA (BOAS), n. 2.379 (2019) 183-184.

24 Datos ofrecidos por nuestro amigo, antiguo alumno y compañero del claustro de profesores de la Facultad de Teología San Isidoro de Seviila, Antonio Bueno Ávila. Desde estas páginas mi más profundo agradecmiento por su generosidad y ayuda prestada en sus datos personales y de la Escuela, que nos han sido de gran utilidad para la redacción de este artículo.

25 Fondo documental del Centro de Estudios Teológicos de Sevilla. Trabajos de síntesis teológicas. Curso 2001/02. 
de Jn 1, 16". Durante sus años de estudios en Roma residió en el Pontificio Colegio Español de San José.

Tras su regreso a la diócesis, en 2007 fue nombrado formador del seminario conciliar de Sevilla hasta 2010. A la vez, en 2007 es también nombrado director de la Escuela diocesana de Teología para Seglares, sustituyendo a su anterior y único director, José María Estudillo Carmona. Desde 2007 hasta la creación de la Facultad de Teología San Isidoro de Sevilla en 2019, ha sido profesor del Centro de Estudios Teológicos de Sevilla y profesor invitado de la Universidad de Sevilla (2009-10). Entre sus actividades de carácter pastoral destacamos las siguientes: adscrito al servicio de Asistencia Religiosa de la Universidad de Sevilla (2001-02) y delegado diocesano para el clero y el diaconado permanente de Sevilla (2011). Actualmente es profesor de la Facultad de Teología San Isidoro de Sevilla, del Instituto Superior de Ciencias Religiosas "San Isidoro y San Leandro"y canónigo de la catedral de Sevilla.

Nuestro amigo y compañero, doctor Antonio Bueno Ávila, siguió como director de la Escuela diocesana de Teología para Seglares, ya integrada en el Instituto Superior de Ciencias Religiosas San Isidoro y San Leandro, hasta su extinción en el curso académico 2013/14. Continuó como director del Instituto hasta el 15 de junio de 2020, siendo nombrado el doctor Pablo Antonio Díez Herrera, sacerdote diocesano, como nuevo director.

\section{SECRETARIOS}

Como nos comenta la Revista de los 25 de la Escuela, los secretarios han sido"colaboradores generosos del Director y de los Profesores, amigos respetuosos de todos los alumnos, siempre dispuestos a echar una mano en tareas complementarias, como Administración o Biblioteca, y, TODO, por puro servicio a la Iglesia y a la promoción de los Seglares" 26 .Y el que esto escribe es testigo de esta afirmación y creo que se queda corta ${ }^{27}$. En el siguiente cuadro ofrecemos la relación de los secretarios de la Escuela diocesana de Teología para

26 Revista Escuela Diocesana de Teología para Seglares. 25 años al servicio de la Iglesia en Sevilla (1994) 27.

27 Algunos de estos secretarios recibieron la ordenación sacerdotal: Pedro Juan de Dios Álvarez Barrera y mi alumno Justo Pérez Alcántara, de feliz memoria. Con los cuatro últimos he mantenido siempre unas relaciones muy cordiales: José 
Seglares desde 1968, fecha de su erección, hasta el curso 2013-14, fecha de su extinción definitiva.

\begin{tabular}{|l|c|}
\hline SECRETARIOS DE LA ESCUELA (1968-2014) \\
\hline Nombre & Años \\
\hline Tirso Muñoz & - \\
\hline Jorge Ogalla & 1 \\
\hline Juan Organvidez & 3 \\
\hline Antonio Gala & 1 \\
\hline Antonio Mendoza & 2 \\
\hline Enrique Bayón & 2 \\
\hline Pedro Juan Álvarez Barrera & 3 \\
\hline Justo Pérez Alcántara & 1 \\
\hline José Sánchez Moreno & 5 \\
\hline Ángel Monaga Medina & 4 \\
\hline Antonio González Álvarez & 27 \\
\hline María Rocío González León & 15 \\
\hline
\end{tabular}

Como podemos observar en el cuadro, 12 han sido los secretarios que han pasado por la Escuela desde 1968 a 2014. Solamente 2 han permanecido durante más tiempo: Antonio González Álvarez desde 1989 hasta 2015 y Rocío González León desde 1995 hasta el cierre de la Escuela en 2014 y desde 2011 hasta el día de hoy como secretaria en el I.S.C.R. San Isidoro y San Leandro de Sevilla. Como vemos, todos seglares, de estados diversos y de distintos niveles académicos y culturales. Todos ellos comprometidos con la Iglesia de Sevilla. Han servido en distintas funciones como secretarios, administración, biblioteca ${ }^{28}$, etc. Algunos de los alumnos encuestados

Sánchez Moreno, de feliz memoria, Ángel Monaga Medina, Antonio González Álvarez y Rocío González León.

28 Por otra documentación y por mi vivencia personal, sabemos que nuestro alumno Félix José Amo Molina, actual párroco de Santa María y San Miguel de Alcalá de Guadaíra, fue durante un tiempo bibliotecario de la Escuela diocesana de Teología para Seglares. Estudió la carrera eclesiástica en el seminario metropolitano de Sevilla y recibió la ordenación sacerdotal en Sevilla el 22 de diciembre de 1988. El 3 de febrero de 1989 celebró una misa en la capilla del seminario para los alumnos de la Escuela. El horario de la biblioteca era de 18,30 a 20,30 lunes, martes y miércoles. 
subrayan la ejemplar organización administrativa de la Escuela y su exquisito trato con los alumnos. Hablaremos, brevemente, de cuatro secretarios: José Sánchez Moreno, Ángel Monaga, Antonio González Álvarez y Rocío González León.

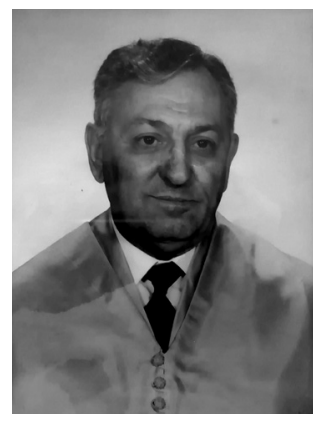

José Sánchez Moreno

\section{1. José Sánchez Moreno}

Jóse Sánchez Moreno nació en 1930 en Melilla ${ }^{29}$, quedando huérfano de padre a la edad de 6 años, pues éste era militar republicano de alta graduación y, tras un consejo de guerra en los primeros días del golpe de estado de 1936, su padre fue fusilado, teniendo que huir rápidamente su madre con sus dos hijos de 4 y 6 años hacia Sevilla. Una vez en Sevilla, fue educado bajo la fe cristiana por una madre luchadora por las creencias del padre. Como casi todo los hombres de su época, empezó a trabajar a edad muy temprana, pero siempre hubo en él un gran interés por aprender y estudiar. A los once años comenzó a estudiar en la Escuela de Aprendices de la Fabrica sevillana "Hispano Aviación", terminando sus estudios como delineante en esta Escuela y continuando trabajando en la factoría durante 27 años. En aquella epóca fue uno de los fundadores del "Montepio" (asociación que se crea por los propios obreros). Esta asociación paliaba las necesidades económicas de las distintas adversidades de la clase trabajadora. El 12 de julio de 1957 se casa con Dolores García Martín, con quien tuvo dos hijas (Charo y María José). En 1968 se hace socio de la Asociación de Ejercitantes Nuestra Señora del Rocio, fundada por Ignacio Gómez Millán. Por aquel entonces, nos comentan sus hijas, había una delegación de pastoral en la archidiócesis, que recuerdan con mucho cariño, pues consistía en reuniones de tres o cuatro

29 Datos ofrecidos por sus hijas Charo y María José con las he conservado una gran amistad por tareas pastorales, ciclos de conferencias, charlas formativas, visitas culturales y convivencias en Sevilla y Mazagón. Siempre conté con la amistad y confianza de su familia. Con mucha frecuencia hablé con José Sánchez Moreno, a quien impartí durante varios años conferencias y ejercicios espirituales en la Asociación de Ejercitantes Nuestra Señora del Rocío, siendo testigo de su amor a su familia, a la cultura y al saber. 
matrimonios, alternándose cada sábado en las casas de dichas familias para hablar y leer la Biblia.

En 1972, tras la fusión de Hispano Aviación y Construcciones Aeronáuticas, muchos obreros fueron despedidos. Sánchez Moreno se presentó a una convocatoria del Banco Vizcaya para nuevos empleados. Aquí trabajó 20 años hasta su jubilación. En 1982 se matriculó en la Escuela diocesana de Teología para Seglares, donde disfrutó mucho con los estudios y lecturas, aclarando muchas de sus dudas que siempre le acompañaron. Al terminar sus estudios, José María Estudillo le pidió que asumiera la secretaría de la Escuela como secretario. Ejerció este oficio hasta 1991, al sobrevenirle una enfermedad que, por momentos, perdía el control mental (encefalopatía), falleciendo de esta enfermedad en diciembre de 1997. Según su familia, siempre prestaba su ayuda a todo necesitado, de forma humilde y callada. Respetó las decisiones y actitudes de sus hijas, aunque no coincidieran con las suyas. Dejó un excelenrte recuerdo en la Asociación de Ejercitantes, a la que ayudó desde la contabilidad en cargos directivos.

\section{2. Ángel Monaga Medina}

Nació el 3 de febrero de 1.965 en el antiguo Hospital de las Cinco Llagas de Sevilla ${ }^{30}$. Toda su vida ha transcurrido, prácticamente, en el barrio de Madre Dios. Estudío la EGB en el colegio parroquial Blanca Paloma, de la popular barriada de los Pajaritos, y posteriormente estudió auxiliar administrativo y teología en la Escuela diocesana de Teología para Seglares, donde colaboró como secretario durante cuatro años. Se casó el 20 de marzo de 1994 y fruto de su matrimonio son sus dos hijos. Laboralmente ha trabajado en muchos campos: bordados Foronda, hipermercados Pryca, la biblioteca del Centro de Estudios Teologicos de Sevilla, secretaría de la Escuela diocesana de Teología para Seglares, Consejería de hacienda de la Junta de Andalucía. Y, desde hace 24 años, trabaja como conserje en la Fundación San Pablo Andalucia, CEU, en Bormujos (Sevilla).

30 Datos ofrecidos por Ángel Monaga Medina, amigo y antiguo compañero de trabajo en el CES "Cardenal Spínola" CEU de Bomujos (Sevilla). Desde estas páginas, agradecemos públicamente a nuestro amigo Ángel la ayuda prestada por sus datos personales y de la Escuela diocesana de Teología para Seglares, de la que es gran conocedor. 


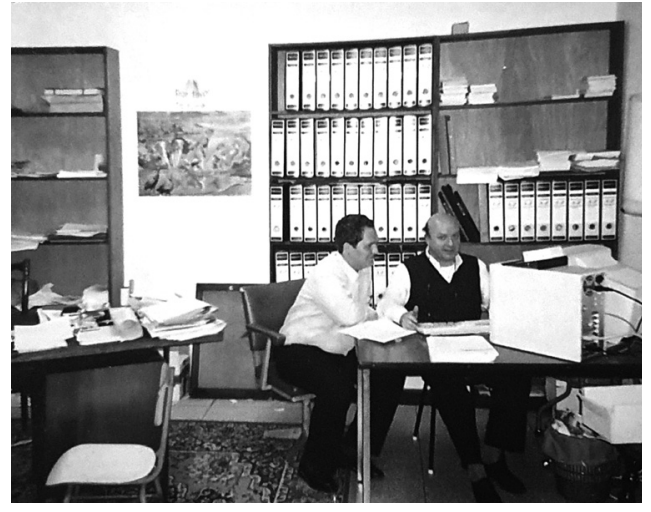

Ángel Monaga y Antonio González

Pastoralmente ha desarrollado y desarrolla toda su labor en la parroquia de la Blanca Paloma, hoy unificada con la de Nuestra Señora de la Candelaria. Su integración en la Blanca Paloma fue gracias a los padres filipenses cuando la comunidad del Oratorio se hizo cargo de la misma. En ella ha colaborado en: pastoral de la salud, liturgia, secretaría de la parroquia y catequesis, donde lleva mas de 35 años con dicha labor, siendo además coordinador arciprestal de catequesis. También, a nivel arciprestal, trabaja en Cáritas.

Con la comunidad filipense vivió una experiencia religiosa durante tres años como aspirante para ingresar en el Oratorio San Felipe Neri de Sevilla. A nivel espiritual está vinculado al Oratorio seglar de San Felipe Neri de Sevilla. El Oratorio seglar es una institución creada en 1992, con motivo del congreso internacional oratoriano.

\section{3. Antonio González Álvarez}

Antonio González Álvarez comenzó a colaborar a partir del curso 1988-89 con el Centro de Estudios Teológicos de Sevilla, siendo rector el doctor Miguel Oliver Román y su secretario Francisco Martín Rodríguez, Oblato de María Inmaculada ${ }^{31}$. Antes de iniciar su colaboración en el Centro de Estudios Teológicos, había sido jefe de personal en varias empresas y administrador de un hotel. Era graduado social. A partir del curso 1990-91, comenzó a trabajar en la biblioteca del Centro de Estudios Teológicos por la mañana y por las tardes en la Escuela con la ayuda de Ángel Monaga Medina. Durante cinco años contó con la ayuda de Ángel Monaga, antiguo alumno de la Escuela y conserje del CEU de Sevilla. En 2005 dejó la biblioteca por

31 Datos ofrecidos por Antonio González Álvarez, amigo y compañero en el Centro de Estudios Teológicos y en la Escuela, a quien agradecemos su ayuda en estos datos y en su tarea como bibliotecario del CET tanto en el palacio de San Telmo como en el nuevo edificio del seminario. 
la edad y se concentró en la Escuela con José María Estudillo y desde 2007 con Antonio Bueno Ávila, colaborando en la puesta en marcha del Intituto Superior de Ciencias Religiosas. En 2015 cesó por voluntad propia, aunque siguió colaborando desde su casa con el Instituto.

\section{4. Rocío González León}

Rocío González León comenzó como secretaria de la Escuela diocesana de Teología para Seglares desde el curso 1995-96 hasta su extinción en 2014². Durante los primeros años compatibilizó sus estudios de derecho en la facultad con sus funciones en la secretaría: atención al público tanto alumnos como profesores, matriculación del alumnado, gestión de exáme-

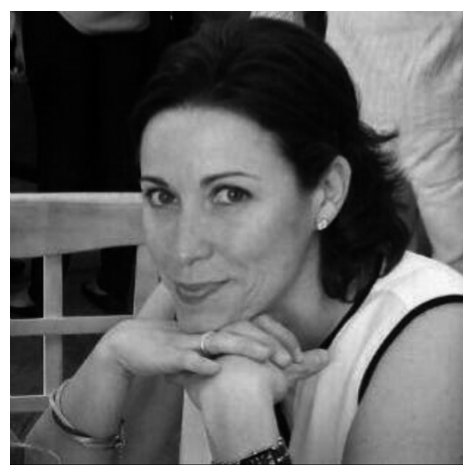

Rocío González León nes, actas académicas, certificados de estudio, orientación a los alumnos, etc. En estos años la Escuela tenía gran demanda. Los cursos eran muy numerosos y, debido a la limitación de los espacios en las"caracolas" de los jardines del palacio de San Telmo, había lista de espera. Su trabajo lo llevó a cabo con los dos directores de la Escuela: José María Estudillo Carmona (1968-2007) y Antonio Bueno Ávila (2007-2014). Como secretaria participó, juntamente con Antonio Bueno y Antonio González Álvarez, su padre, en la puesta en marcha del Instituto Superior de Ciencias Religiosas, del que es secretaria desde su creación en el curso 2011-12 hasta el día de hoy, ya integrado en la Facultad de Teología San Isidoro de Sevilla. En esta última fase ha ido ampliando paulatinamente sus funciones hasta realizar todas la labores de la secretaría.

32 Datos que nos han sido facilitados por Rocío González León, actual secretaria de la Facultad de Teología San Isidoro de Sevilla y gran conocedora de la historia, directores, alumnos y profesores de la Escuela diocesana de Teología para Seglares. A ella se debe, en gran parte, la conservación de los fondos documentales de la Escuela diocesana de Teología para Seglares y los del Instituto Superior de Ciencias Religiosas San Isidoro y San Leandro de Sevilla. Desde estas páginas, mi más sincero y público agradecimiento. 


\section{PROFESORADO}

\section{1. Los primeros profesores (1968-1984)}

Son muchos los profesores que han impartido clases en la Escuela diocesana de Teología para Seglares desde 1968 hasta el día de hoy. En el primer año de la Escuela, 1986-69, tenemos 9 profesores: Juan Guillén Torralba, Ángeles Sáinz Martín, José María Delgado, Celestino Rivera Aroca, Francisco Díaz Rodríguez, Jesús Domínguez Gómez, Francisco Gil Delgado, Valentín Vigueras Franco y Jesús Borrego Arruz ${ }^{33}$.

En el curso 1971-72 el claustro de profesores estaba formado por las siguientes personas ${ }^{34}$ : Jesús Borrego Arruz (salesiano), Antonio Brajones Cubiles (Cádiz-Ceuta), Luis Briones Gómez (Córdoba), Diego Capado (Huelva), José María Delgado, Francisco Díaz Rodríguez (Sevilla), Miguel Ángel Díez de Palencia (capuchino), José María Estudillo Carmona (Sevilla), Celestino Rivera Aroca (salesiano), Antonio García del Moral (dominico), José María Garrido Luceño (Sevilla), Juan Garrido Mesa (Sevilla) Francisco Gil Delgado (Sevilla), Antonio González Dorado (jesuita), Juan Guillén Torralba (Sevilla), Antonio Ismael García (dominico), José Morales Carmona (Sevilla), Manuel del Trigo Campos (Sevilla) y Valentín Vigueras Franco (salesiano) ${ }^{35}$. Todos eran sacerdotes.

En los primeros años de la Escuela, además de los iniciadores, encontramos profesores de varias diócesis. Entre ellos figuran sacerdotes de las cuatro diócesis de la Andalucía Occidental (Sevilla, Córdoba, Huelva y Cádiz-Ceuta) y religiosos de varias órdenes y congregaciones: carmelitas calzados, salesianos, dominicos, franciscanos y capuchinos. Mencionamos, entre ellos: Agustín Cabrera (Sevilla), Samuel Camba (salesiano), Antonio Cuesta (salesiano), Carlos Escudero (salesiano), Jesús Domínguez Gómez (Sevilla y futuro obispo de Coria-Cáceres), Baldomero García (Huelva), Ángel

33 Fondo documental de la Escuela diocesana de Teología para Seglares. Sección I: Gobierno-Correspondencia, caja n. 2.

34 Muchas de estas personas fueron profesores míos desde 1965 a 1971 y, con más de la mitad, he sido posteriormente compañero durante muchos años en el claustro del profesores, sobre todo con José María Estudillo Carmona, José María Garrido Luceño, Juan Guillén Torralba, José Morales Carmona y Valentín Vigueras Franco.

35 Revista Escuela Diocesana de Teología para Seglares. 25 años al servicio de la Iglesia en Sevilla (1994) 23; Fondo documental de la Escuela diocesana de Teología para Seglares. Sección I: Gobierno-Correspondencia, caja n. 2. 
Gómez Guillén (Sevilla), Francisco Lozano Sebastián (Sevilla y futuro nuncio apostólico), Juan Mairena Valdayo (Huelva), Isidoro Manzano (franciscano), Herminio de Paz Castaño (dominico), Raimundo Rincón (Murcia) y Jaime Andrade (carmelita calzado). Como seglar solamente contamos con una persona: Ángeles Sáinz Martín.

\section{2. Profesores (1985-1993)}

En el curso 1985-86 tenemos los siguientes profesores: Miguel de Burgos Núñez (el evangelio de Jesús), Antonio Calero de los Ríos (eclesiología), José Maria Garrido Luceño (fe y compromiso del cristiano), José María Estudillo Carmona (liturgia, religión y religiones en el mundo de hoy), Gonzalo Flor Serrano (iniciación a la Biblia), Francisco Rodríguez Fassio (los sacramentos de iniciación cristiana), Francisco Gil Delgado (los sacramentos del orden y del matrimonio), Antonio Muñoz Sánchez (historia de las Iglesias cristianas), José María de los Santos López (doctrina social de la Iglesia), Enrique Aguiló Bonín (teología moral fundamental y personal), Juan Guillén Torralba (los temas clave del antiguo testamento y el profetismo en la Biblia), Carlos Martín Hernández (vida cristiana y acción pastoral hoy), Francisco Martín Rodríguez (cristología y teología de la liberación), Roberto Miralles Seguí (cristianismo y cultura contemporánea) y Miguel Oliver Román (introducción a la teología cristiana y los temas clave del nuevo testamento).

En el curso 1987-88 figuran como nuevos profesores: Luis Fernando Álvarez González (inicación a la celebración de la fe), VíctorVidal y José Miguel Sopeña (sacramentos de la iniciación cristiana), Jesús Duque Fernández (doctrina social de la Iglesia), José Blanco Gálvez (los seglares: su compromiso en el mundo), Jesús Colombo Roquette (teología moral fundamental y persona), Pedro León Moreno (eucaristía: aspectos teológicos y pastorales), Manuel Mallofret Lancha (los Hechos de los Apóstoles y Pablo), y Jesús Pérez Saturnino (los seglares: vocación y misión en la Iglesia). Hay que mencionar que la mayor parte de estos nuevos profesores, se habían incorporado anteriormente al Centro de Estudios Teológicos. En el curso 1988-89 se incorporan dos historiadores, ya profesores en el Centro de Estudios Teológicos: José González Sáinz de la Maza (historia de la Iglesia antigua y medieval) y Manuel Martín Riego (historia de la Iglesia moderna y contemporánea). En los cursos siguientes se van incorporando nuevos profesores: Francisco de Llanos 
Peña (oratoriano), Francisco Ortiz Gómez (Sevilla) y Francisco Javier Fernández de Liencres (Sevilla).

\section{3. Profesores (1993-94)}

En el curso académico 1993-94 figuran 22 profesores, de los que 8 eran doctores y los 14 restantes licenciados en sus respectivas materias. Los profesores con más años de docencia eran: José María Estudillo Carmona (25 años), Juan Guillén Torralba (25), Miguel Oliver Román (25) y José María Garrido Luceño (24). Los cuatro eran sacerdotes de la diócesis de Sevilla. En el siguiente cuadro ofrecemos la relación de los 22 profesores, juntamente con sus materias ${ }^{36}$.

\begin{tabular}{|l|l|}
\hline \multicolumn{2}{|c|}{ PROFESORES (1993-94) } \\
\hline Profesor & Materia \\
\hline Aguiló Bonín, Enrique (+) & Teología fundamental \\
\hline Álvarez González, Luis Fernando & Liturgia e inicación a los sacramentos \\
\hline Blanco Gálvez, José & Laicología \\
\hline De Burgos Núñez, Miguel & Evangelio de Jesús \\
\hline Calero de los Ríos, Antonio María (+) & Eclesiología \\
\hline Camacho Acosta, Fernando & Seminario especial sobre evangelios \\
\hline Colombo Roquette, Jesús (+) & Teología de moral fundamental \\
\hline Estudillo Carmona, José María & $\begin{array}{l}\text { Historia de las religiones y Sacram. } \\
\text { Penitencia }\end{array}$ \\
\hline Fernández de Liencres, Francisco J. & Sacramento del matrimonio \\
\hline Flor Serrano, Gonzalo & Antiguo Testamento \\
\hline Garrido Luceño, José María & Fe y compromiso del cristiano \\
\hline González Sáinz de la Maza, José A. & Historia de la Iglesia antigua y medieval \\
\hline Guillén Torralba, Juan (+) & Pentateuco y libros históricos y profetas \\
\hline León Moreno, Pedro & Escatología \\
\hline De Llanos Peña, Francisco & Sacramento de la unción \\
\hline Mallofret Lancha, Manuel & Hechos de los Apóstoles y San Pablo \\
\hline Martín Riego, Manuel & $\begin{array}{l}\text { Historia de la Iglesia moderna y } \\
\text { contemporánea }\end{array}$ \\
\hline Martín Rodríguez, Francisco (+) & El Dios de la revelación y cristología \\
\hline Miralles Seguí, Roberto & Doctrina social de la Iglesia \\
\hline Oliver Román, Miguel & Nuevo Testamento \\
\hline Ortiz Gómez, Francisco & Sacramento del orden \\
\hline Rodríguez Bernal, Amalia & Sacramento de la unción \\
\hline
\end{tabular}

36 Revista Escuela Diocesana de Teología para Seglares. 25 años al servicio de la Iglesia en Sevilla (1994) 22. 
De estos 22 profesores, 8 eran doctores y los 14 restantes licenciados en las materias que impartían. Del total de profesores, 10 eran sacerdotes de la diócesis de Sevilla, 2 sacerdotes salesianos, 2 sacerdotes dominicos, un sacerdote Oblato de María Inmacudada, un sacerdote franciscano, un sacerdote del Oratorio de San Felipe Neri y 5 seglares.

\section{4. Profesores (2007-08)}

En el curso 2007-08 el claustro de profesores de la Escuela diocesana de Teología para Seglares estaba formado por 25 docentes, de los que 12 eran doctores y los 13 restantes licenciados en el área de sus respectivas materias. En el siguiente cuadro ofrecemos la relación de profesores del curso académico 2007-08, juntamente con las materias que impartían.

\begin{tabular}{|l|l|}
\hline \multicolumn{2}{|c|}{ PROFESORES (2007-08) } \\
\hline Profesor & Materia \\
\hline Alcober Brenchat, José María & Introducción al misterio de Dios \\
\hline Álvarez González, Luis Fernando & Sacramentos de la iniciación cristiana \\
\hline Álvarez Paulino, Miguel Ángel & Pentateuco y libros históricos \\
\hline Bueno Ávila, Antonio & Teología fundamental \\
\hline Camacho Acosta, Fernando (+) & Cristología bíblica \\
\hline Cotrino Bautista, Manuel & Sacramento de la penitencia \\
\hline Estudillo Carmona José María (+) & $\begin{array}{l}\text { Historia de la salvación en grandes } \\
\text { religiones }\end{array}$ \\
\hline Fernández Liencres, Francisco J. (+) & Sacramento del matrimonio \\
\hline Flor Serrano, Gonzalo (+) & Introducción al Antiguo Testamento \\
\hline García de la Mata, José Luis & $\begin{array}{l}\text { Historia de la Iglesia: antigua, media, mo- } \\
\text { derna y contemporánea }\end{array}$ \\
\hline Garrido Luceño, José María (+) & Vida teologal \\
\hline Garzón Moreno, Miguel Ấngel & Libros proféticos \\
\hline Guerra Martínez, Antonio & Salmos: la oración del hebreo \\
\hline Hernández Martínez, Eugenio (+) & Moral fundamental \\
\hline León Moreno, Pedro (+) & Escatología (la plenitud de los tiempos) \\
\hline Llanos Peña, Francisco & Sacramento de la unción de los enfermos \\
\hline Mallofret Lancha, Manuel & $\begin{array}{l}\text { El apóstol Pablo en la historia del cristianis- } \\
\text { mo primitivo }\end{array}$ \\
\hline Pascual Rodríguez, Antero & Sacramento del orden sacerdotal \\
\hline Pérez de Ayala Conradi, Mariano & Doctrina social de la Iglesia \\
\hline Pereira Delgado, Álvaro & Cartas paulinas \\
\hline Rodríguez Bernal, Amalia & Sacramento de la unción de los enfermos \\
\hline Román Villalón, Álvaro & Eucaristía \\
\hline Rueda Gómez, Luis & Liturgia fundamental \\
\hline Ruiz Pérez, María Dolores & Introducción al Nuevo Testamento \\
\hline Sánchez Solís, Ángel & Eclesiología. La Iglesia en el mundo \\
\hline
\end{tabular}


En el curso académico 2007-08 tenemos en la Escuela diocesana de Teología para Seglares 25 profesores: 12 doctores, 12 licenciados y un licenciado con un master en docrina social de la Iglesia. De estos 25 profesores, 16 eran sacerdotes de la diócesis de Sevilla, 2 sacerdotes salesianos, 2 sacerdotes del Oratorio de San Felipe Neri, un sacerdote dominico, un sacerdote de la Congregación de los Misioneros de África Padres Blancos, una hija de María Auxiliadora y 2 seglares (una mujer y un hombre). Todos ellos graduados en las materias que impartían.

El 13 de febrero de 2008, contando con la presencia del cardenal Amigo Vallejo, los siguientes profesores recibieron un homenaje de la Escuela diocesana de Teología para Seglares: Francisco Ortiz Gómez, José María Estudillo Carmona, Luis Fernando Álvarez González, Manuel Cotrino Bautista, Antonio Bueno Ávila, Enrique Aguiló Bonín, José María Alcober Brenchat, Miguel de Burgos Núñez, Antonio Calero de los Ríos, Manuel Castro Román, Ignacio Jesús Colombo Roquette, Pablo Antonio Díez Herrera, Francisco Javier Fernández de Liencres, Gonzalo Flor Serrano, José Luis García de la Mata, José María Garrido Luceño, Miguel Ángel Garzón Moreno, José Antonio González Sáinz de la Maza, Francisco de Llanos Peña, Manuel Mallofret Lancha, Francisco Martín Rodríguez, José Morales Carmona, Miguel Oliver Román, Mariano Pérez de Ayala Conradi, Amalia Rodríguez Bernal, Francisco Rodríguez Fassio, Luis Rueda Gómez, María Dolores Ruiz Pérez, Ángel Sánchez Solís, Rosa Carbonell de la Fuente, Ignacio Gaztelu Pastor, Jesús Duque Fernández, Manuel Palma Ramírez, Antero Pascual Rodríguez, José Miguel Núñez Moreno, Pedro León Moreno, Roberto Miralles Seguí y Manuel Martín Riego.

\section{5. Profesores en el curso 2010-11}

En el curso académico 2010-11, ya casi de los últimos del funcionamiento de la Escuela diocesana de Teología para Seglares tenemos los siguientes profesores: Antonio Bueno Ávila, Gonzalo Flor Serrano, Miguel Ángel Álvarez Paulino, José María Alcober Brenchat, María Dolores Ruiz Pérez, Luis Rueda Gómez, Jesús Luis García de la Mata Calvo, José María Garrido Luceño, Mariano Pérez de Ayala Conradi, Antero Pascual Rodríguez, Francisco Javier Fernández de Liencres, Álvaro Pereira Delgado, Luis Fernando Álvarez González, Ángel Sánchez Solís, Eugenio Hernández Martínez, Fernando Camacho Acosta, José María Estudillo Carmona, Miguel Ángel Garzón Moreno, 
Manuel Mallofret Lancha, Manuel Cotrino Bautista, Francisco de Llanos Peña, Amalia Rodríguez Bernal, Adolfo Lucas Maqueda, Pedro León Moreno, Antonio Guerra Martínez y Álvaro Román Villalón ${ }^{37}$. En el curso 2011-12 tenemos un nuevo profesor: Miguel Vázquez Lombo con la asignatura sacramento del orden sacerdotal ${ }^{38}$. En el curso 2013-14 se extingue la Escuela diocesana de Teología para Seglares. Sus últimos profesores fueron: Luis Rueda Gómez (sacramento de la penitencia); los laicos, su misión en la Iglesia y en el mundo (José María Estudillo Carmona); Francisco de Llanos Peña y Amalia Rodríguez Bernal (sacramento de la unción de los enfermos); escatología (María Dolores Ruiz Pérez); historia de la Iglesia moderna y contemporánea (José Luis García de la Mata); el apóstol Pablo en la historia del cristianismo primitivo (Manuel Mallofret Lancha); sacramento de la eucaristía (Álvaro Román Villalón).

\section{ALUMNADO}

\section{1. Alumnos (1968-2014)}

Al cumplirse los 25 años de la Escuela (1993-94) el total de alumnos matriculados llegó a 5.892. El curso académico con menor número de alumnos fue el año fundacional, es decir, el curso 1968-69, con 75 estudiantes. Y el curso con mayor número de alumnos fue el de 1988-1989 con 430 estudiantes. Desde 1968-69 al 1993-94 los alumnos matriculados en la Escuela diocesana de Teología para Seglares están comprendidos en la siguiente horquilla de edades ${ }^{39}$ :

- $\quad$ Más de 1.500 alumnos entre 21 y 30 años.

- Unos 2.000 alumnos entre 31 y 40 años.

- $\quad$ Cerca de 1.000 alumnos entre 41 y 50 años.

37 Fondo documental de Instituto Superior de Ciencias Religiosas San Isidoro y San Leandro. Memoria de la Escuela diocesana de Teología para Seglares (1968/1969 y 2009/2010). Se trata de un documento para uso interno; Fondo documental de la Escuela diocesana de Teología para Seglares. Sección II: Gestión Académica y Organización de la Docencia-Programas de las Asignaturas, caja n. 3 (1968-2011).

38 Fondo documental de la Escuela diocesana de Teología para Seglares. Sección II: Gestión Académica y Organización de la Docencia-Libros de Actas, n. 8. Actas del curso 2010-11 al 2013-14.

39 Revista Escuela Diocesana de Teología para Seglares. 25 años al servicio de la Iglesia en Sevilla (1994) 14. 
En estos 25 años (curso 1968-89 al 1993-94) tenemos alrededor de 6.000 alumnos inscritos, de los que casi 4.000 han sido mujeres. En los primeros años predominaban las religiosas de muchas formas de vida consagrada. Poco a poco son superadas por los seglares. Las profesiones o dedicaciones del alumnado son muy variadas: religiosos y religiosas, titulados superiores, empresarios, hermanos mayores de hermandades y cofrades, militares, titulados medios, profesores universitarios, de primaria y enseñanzas medias, profesionales del comercio, trabajadores manuales, estudiantes y un buen número de amas de casa.

A pesar de que el objetivo fundamental de la Escuela era la formación teológica de los estudiantes, entre las metas que se proponían los que realizaban los cuatro cursos era la obtención de un diploma. La Escuela concedía a los alumnos que superaban las pruebas establecidas un diploma diocesano de aptitud en cultura religiosa superior, firmado por el arzobispo, el rector del Centro de Estudios Teológicos y el director de la Escuela. En los primeros veinticinco años de la Escuela se habían diplomado 759 alumnos: 151 hombres y 608 mujeres (incluidas religiosas) ${ }^{40}$. Desde la creación de la Escuela hasta el curso 2007-08 tenemos un total de 1.148 alumnos diplomados. Como podemos observar, la mayor parte de los alumnos ponían su meta en la formación como cristianos y compartir sus conocimientos con sus familias, parroquias y otros ámbitos. Muchos de estos alumnos son cristianos comprometidos en sus parroquias, movimientos apostólicos, Cáritas parroquial o diocesana, pastoral sanitaria, catequesis, equipos de liturgia, pastoral penitenciaria, ayuda y colaboraciones con inmigrantes, etc. También en eventos extraordinarios de la diócesis: Sínodo diocesano hispalense (1973), congreso internacional de catequesis (1992), congreso eucarístico internacional (1993), asamblea de laicos (2007), campañas de Cáritas, campaña contra el Sida, etc.

Entre estos alumnos comprometidos con la Iglesia y la sociedad mencionamos a los diáconos permanentes. En 1994 tenía la diócesis de Sevilla 25 diáconos permanantes. Para acceder a dicha ordenación, todos debieron realizar cuatro años de estudios teológicos pastorales. La Escuela diocesana de Teología para Seglares fue la encargada de la formación de los diáconos permanentes: de los 19 diáconos

$40 \quad$ Ibid. 19. 
ordenados entre 1981 y 1991 y de los 6 ordenados en 1994, todos realizaron sus estudios en la Escuela. Todos han ejercido o siguen ejerciendo su misión diaconal en parroquias urbanas o rurales ${ }^{41}$.

Encontramos en las fichas o expedientes académicos de la Escuela alumnos que se matricularon durante un curso o varios, ingresando posteriormente en el seminario y recibiendo más tarde la ordenación sacerdotal. Tales son los casos, entre otros, de José Joaquín Sierra Silva, Emilio Morejón Camacho, Florentino Córcoles Calero, José Manuel Escamilla Prieto y Manuel Velázquez Limón ${ }^{42}$. Todos pertenecen al clero diocesano. Mencionamos también a Javier Muruve Fernández-Piedra, de la Congregación del Oratorio San Felipe Neri de Sevilla, que estudió en la Escuela dos cursos: 1988-89 y 1989-90. También nos encontramos a seminaristas que, tras abandonar el seminario, se matricularon en la Escuela diocesana de Teología para Seglares, entre ellos Antonio Prieto Ayllón, natural de Santiponce (Sevilla), Antonio Romero Páez, natural de Los Palacios (Sevilla) y Vicente Almeida Payán, natural de Sevilla ${ }^{43}$. Entre los seglares figuran muchos alumnos que posteriormente me he encontrado ayudando en sus parroquias, movimientos apostólicos, colegios públicos

41 Ibid.

42 Fondo documental de la Escuela diocesana de Teología para Seglares. Sección II: Gestión Académica y Organización de la Docencia-Expedientes Académicos, caja n. 8 (SZ); Fondo documental de la Escuela diocesana de Teología para Seglares. Sección II: Gestión Académica y Organización de la Docencia-Fichas de Alumnos, nn. 16 y 18. José Joaquín Sierra Silva, natural de Villanueva del Ariscal (Sevilla), fue alumno de la Escuela desde el curso académico 1993/94 al 1997/98. Tras realizar algunas asignaturas por tutoría, recibió la ordenación sacerdotal el 17 de septiembre de 2000. Emilio Morejón Camacho, natural de Sevilla y viudo, fue alumno en el curso 1994-95, recibiendo la ordenación sacerdotal el 9 de septiembre de 1999. Florentino Córcoles, natural de Sevilla y alumno de la Escuela en el curso 1994-95, recibió la ordenación sacerdotal el 17 de septiembre de 2000. José Manuel Escamilla Prieto, natural de Umbrete (Sevilla), estuvo matriculado en la Escuela desde 1985 a 1988. Ingresó en el seminario de Sevilla y se ordenó de sacerdote el 19 de septiembre de 1999. Por último, Manuel Velázquez Limón, natural de Coría del Río (Sevilla), se matriculó en la Escuela en primero en el curso 1999/2000. Ingresó en el seminario y estudió en el Centro de Estudios Teológicos de Sevilla. Posteriormente recibió la ordenación sacerdotal en septiembre de 2010. A todos ellos les impartí las asignaturas de historia de la Iglesia moderna y contemporánea.

43 Fondo documental de la Escuela diocesana de Teología para Seglares. Sección II: Gestión Académica y Organización de la Docencia-Fichas de Alumnos, caja n. 18. Antonio Prieto Ayllón y Antonio Romero Páez fueron compañeros míos de 1966 a 1968 en el seminario metropolitano de Sevilla. 
y religiosos, pastoral de enfermos, liturgia, Cáritas, etc. Entre ellos queremos mencionar a nuestro amigo Joaquín Soto Gómez, natural de Sevilla. Estudió en la Escuela desde el curso 1988-89 al 1991-92, finalizando los cuatro años de teología. Perteneciente a los equipos de Nuestra Señora y, ya jubilado, colaboró 19 años como secretario del Centro de Estudios Teológicos de Sevilla. Por ello, con fecha 25 de enero de 2006, la junta de patronos del CET le concedió la medalla de oro ${ }^{44}$.

Por la Escuela diocesana de Teología para Seglares han sido más de 10.000 los estudiantes que han pasado por ella ${ }^{45}$. En el curso académico 2008-2009 el número de estudiantes matriculados supera los 190 alumnos, en el de 2009-10 son 195 y en el curso 2010-11 son 178 alumnos. Además, con el deseo de ofrecer una formación permanente a sus antiguos alumnos, la Escuela también organiza Cursos de Actualización sobre temas de actualidad, colaborando con el Centro de Estudios Teológicos en la organización de las Jornadas Teológicas. Nos hubiera gustado tener la documentación para poder ofrecer una relación completa de los alumnos matriculados en la Escuela desde 1968 a 2014. No ha sido posible y hemos optado por acercarnos al número de alumnos de determinados cursos académicos.

En 1968-69, curso fundacional, tenemos 75 alumnos, de los que 67 son mujeres y 8 varones. Por condición eclesial: 57 religiosos y religiosas y 18 seglares. La horquilla con más alumnos es la comprendida entre los 25 y 45 años (42 alumnos) y entre 46 a 55 años, 22 alumnos. La mayor parte de estas religiosas, además de formarse personalmente, buscaban una capacitación humana y teológica de cara a impartir las materias propias religiosas en sus respectivos centros docentes. Contrasta la juventud del alumnado en los primeros años de la Escuela, si lo comparamos con los del curso 2010-11. En el curso académico 1993-94 tenemos 158 alumnos, seglares la casi totalidad

44 Dicha medalla ha sido concedida solamente a cinco personas: cardenal Amigo Vallejo, arzobispo de Sevilla y presidente de la junta de patronos del CET; Antonio Calero de los Ríos, rector del CET y profesor de la Escuela; Miguel Oliver Román, rector del CET y profesor de la Escuela; Jesús Colombo Roquette (a título póstumo), secretario del CET y profesor de la Escuela; Joaquín Soto Gómez, colabotador del CET y antiguo alumno de la Escuela diocesana de Teología para Seglares.

45 Fondo documental del Instituto Superior de Ciencias Religiosas San Isidoro y San Leandro de Sevilla. Memoria de la Escuela diocesana de Teología para Seglares (1968/1969 y 2009/2010). Se trata de un documento para uso interno. 
(144 seglares y 14 religiosos/as). Se mantendrá como constante en la historia de la Escuela el predominio del número de matrículas de mujeres (107 hembras y 51 varones en el curso académico 1993-94) ${ }^{46}$.

Entre los 329 alumnos matriculados en el curso 1995/96 tenemos: 120 licenciados, 58 amas de casa, 46 empleados, 15 jubilados, 14 estudiantes, 11 industriales, 9 funcionarios, etc. La edad media de estos 329 alumnos se sitúa en torno a los 40 años. En relación al estado civil tenemos: 150 solteros, 146 casados, 11 viudos y los 22 restantes sin especificar. En relación al sexo: 214 mujeres, 103 varones y los 12 restantes sin especificar ${ }^{47}$. El curso académico con mayor número de alumnos fue el de 1996-97 con 345, de los que 100 estaban matriculados en primero, 80 en segundo, 70 en tercero y los 95 restantes en cuarto.

En el curso 2009-10 tenemos un total de 210 alumnos $^{48}$, de los que 128 son mujeres (6 religiosas) y 82 hombres. Entre las profesiones tenemos: 46 profesores (Infantil/ESO/Universidad), 26 amas de casa, 25 administrativos, 18 jubilados-pensionistas, 17 ingenieros, 10 funcionarios, 7 médicos, 6 economistas, 6 empresarios, 5 trabajadores sociales, 4 enfermeros, 3 estudiantes, 3 farmacéuticos, etc. Por último, en el curso 2010-11 son 218 los alumnos matriculados: 60 son licenciados, 42 jubilados, 36 amas de casa, 30 administrativos, 14 técnicos medios, 12 sanitarios, 8 empresarios, 6 religiosas, 6 del comercio, 3 estudiantes y un operario manual. Por sexo tenemos 140 mujeres y 78 varones y por estado: 118 casados, 65 solteros y 35 viudos. La edad con más alumnos es la comprendida entre los 56 y 60 años (45 alumnos), seguidos por los de entre 46 y 50 (41 alumnos) y entre los 61 y 70 años (39 alumnos). Son muy pocos los jóvenes: 7 alumnos entre 26 y 30 años y 9 entre 31 y 35 años ${ }^{49}$.

La documentación del archivo, como veremos al analizar las cajas de las actas académicas del mismo, refleja la progresiva bajada de alumnos al crearse el 13 de noviembre de 2011, festividad de San Leandro, el Intituto Superior de Ciencias Religiosas "San Isidoro y

46 Revista Escuela Diocesana de Teología para Seglares. 25 años al servicio de la Iglesia en Sevilla (1994) 12-15.

47 Fondo documental de la Escuela diocesana de Teología para Seglares. Sección III: Administración-Libros de ingresos y gastos, caja n. 1 (1995-96).

48 Fondo documental de la Escuela diocesana de Teología para Seglares. Sección III: Administración-Libros de ingresos y gastos, caja n. 1 (2009-2010).

49 Fondo documental de la Escuela diocesana de Teología para Seglares. Sección III: Administración-Libros de ingresos y gastos, caja n. 1 (1995-96). 
San Leandro". A partir de esta fecha, como ya hemos indicado en más de una ocasión, la Escuela diocesana de Teología para Seglares, se iría extinguiendo progresivamente. En el curso 2011-12, ya desaparecido el primer curso, los alumnos de segundo no pasaban de 35, los de tercero de 17 y los de cuarto de 29 en la asignatura que más. El curso académico 2012-13 contó con un total de 29 alumnos: 12 en tercero y 17 en cuarto. Por último, en el curso académico 2013-14, año de la extinción de la Escuela, solamente funciona el curso cuarto con una media de 15 quince, de los que solamente 9 se examinaron ${ }^{50}$.

A través de la lectura y análisis del Libro de Actas de Diplomados, podemos ofrecer el número de diplomados de cada curso académico. La Escuela diocesana de Teología para Seglares otorgó a los largo de su historia 1.225 diplomas. Predominan los títulos de las religiosas en los primeros años y de las mujeres sobre los hombres. En el curso 1969-70, en el que termina la primera promoción, tenemos 46 diplomas de religiosas sobre 62 alumnos y 20 de religiosas sobre 32 alumnos en el curso 1970/71. A partir del curso 1971/72 se suprime el estado concreto, aunque todavía el número de religiosas y religiosos superaba a los seglares. En el curso 1985-86 los alumnos diplomasdos titulados ascienden 46, de los que 32 son mujeres y los 14 restantes hombres. En el curso académico 1987-88 tenemos 68 diplomados, de los que 46 son mujeres y 22 hombres.

En los cursos académicos 1989-90 y 1990-91 se da una drástica bajada de diplomados: 9 y 6 respectivamente. En los siguientes cursos el número de diplomados suele ser bastante elevado, destacando el curso 1992-93 con 43, de los que 33 son mujeres y los 10 restantes hombres. De nuevo otra subida en el curso 1994-95 con 50 diplomados (35 mujeres y 15 hombres) y en el curso 1997-98 un total de 41, de los que 29 son mujeres y 12 hombres. Vuelven a ir bajando en los siguientes cursos académicos, aunque siempre hay alrededor de 15 a 20. A partir del curso 2005-06 se nota una bajada progresiva, siendo raro el curso que supera los 15 diplomados, con la excepción de dos cursos académicos: 2008-09 con 18 diplomados, superando por primera vez la estadística el número de hombres: 5 mujeres y 13 varones. Hay otra subida en el curso 2012-13 con 20 diplomados: 12 hombres y 8 mujeres. Los dos últimos cursos de la Escuela, como es

50 Fondo documental de la Escuela diocesana de Teología para Seglares. Sección II: Gestión Académica y Organización de la Docencia-Libros de Actas, caja n. 8 (2013/14). 
obvio, el número de diplomados es el más bajo de la historia de esta institución: 6 en el curso 2013-14 y 7 en el curso 2014-15.

En las agendas académicas nos encontramos las normas a seguir por los alunmos y profesores de la Escuela. Las normas de régimen interno incluyen los derechos y deberes de los alumnos. Como derechos figuran: asistencia a clase, exámenes, actos académicos, programas gratuitos de las materias, actos celebrativos, participar en otras actividades extraescolares (mesas redondas, conferencias, retiros, convivencias, etc.), uso de todos los servicios e instalaciones del Centro e Estudios Teológicos (previo acuerdo con sus responsables), diplomas o certificados de estudios por los cursos o materias realizados totalmente. Y entre sus deberes: respeto a las normas de funcionamiento establecidas para el bien común de la Escuela, obligación moral de asistencia a clase, máxime si desean examinarse, la mayor participación posible en las actividades y celebraciones organizadas por el centro, espíritu de responsabilidad, de crítica y de colaboración para el bien y mejora progresiva de la Escuela diocesana de Teología ${ }^{51}$.

En la agenda académica del curso 2010-11 se insiste en que esta Escuela está dirigida ${ }^{52}$ :

- $\quad$ a los jóvenes mayores de 18 años.

- a los responsables de grupos y comunidades cristianas: parroquiales, religiosas, populares, etc.

- a educadores, padres de familia, catequistas y animadores de formación.

- a todos los adultos que deseen iluminar, desde el evangelio, sus actividades profesionales, laborales y políticas.

\section{2. Asociación de Antiguos Alumnos "San Telmo"}

Desde 1994 existe la Asociación de Antiguos Alumnos "SanTelmo", la cual está legítimamente constituida y tiene sus propios estatutos ${ }^{53}$.

51 Fondo documental de la Escuela diocesana de Teología para Seglares. Sección II: Gestión Académica y Organización de la Docencia-Programas de las Asignaturas, caja n. 1 (1968-2011).

52 Fondo documental de la Escuela diocesana de Teología para Seglares. Sección III: Administración-Libros de ingresos y gastos, caja n. 1 (2010/11).

53 Fondo documental del Instituto Superior de Ciencias Religiosas San Isidoro y San Leandro. Memoria de la Escuela diocesana de Teología para Seglares (1968/1969 y 2009/2010). Se trata de un documento para uso interno. 
Como Asociación se ha personado en situaciones críticas de la sociedad sevillana y ha tenido voz en el foco de recuperación de la zona marginal del Polígono Sur. Por la documentación conservada, sabemos que el 27 de mayo de 1988 se celebró el primer encuentro con antiguos alumnos, con el objetivo de crear una Asociación de Antiguos Alumnos. Era una idea acariciada por el director y los alumnos de la Escuela. Entre los objetivos tratados en dicha reunión, se citan los siguientes:

- Participar y colaborar en la marcha de la Escuela diocesana de Teología.

- Celebrar en ella encuentros, retiros espirituales y convivencias.

- Organizar y participar en actividades programadas por ellos, por la Escuela o po el Centro de Estudios Teológicos, como son ciclos de conferencias y jornadas teológicas.

- Estar informados e informar a otras personas de las actividades organizadas por la Escuela: convivencias, eucaristías, cursos, mesas redondas, conferencias, etc.

Durante el año organizan distintas actividades: encuentros, visitas culturales, conferencias, celebraciones religiosas asistencia a cursos de actualizacón, etc. Asimismo apoya a la Escuela en diversas facetas: formación permanente, ayudas económicas para la financiación de determinados actos, homenaje al profesorado, etc. En junio de 2002 el presidente era Gabino Alonso Arza, ingeniero industrial ${ }^{54}$. En septiembre de 2007 la presidenta de la Asociación de Antiguos Alumnos era Enriqueta López Lozano. En más de una ocasión algunos miembros de la Asociación becaban con la matrícula a alumnos con menos posibilidades económicas. En concreto, el 11 de febrero de 2010 una antigua alumna de la Asociación "San Telmo" entregó al director de la Escuela la cantidad de 300 auros para becar a una alumna," una vez demostrado su interés por los estudios y atendiendo a sus necesidades personales"

54 Fondo documental de la Escuela diocesana de Teología para Seglares. Seccion II: Gestión Académica y Organización de la Docencia-Expedientes Académicos, caja n. 1 (A/B). Se matriculó en la Escuela en el curso académico 1995/96, finalizando los estudios en el curso 1998/99. Obtuvo su diploma el 6 de abnril de 2000. Estuvo muy comprometido con la Escuela diocesana de Teología para Seglares.

55 Fondo documental de la Escuela diocesana de Teología para Seglares. Sección IV: Varios-Asociación de Antiguos Alumnos"San Telmo". 


\section{ARCHIVO DE LA ESCUELA DIOCESANA DE TEOLOGÍA PARA SEGLARES (1968-2014)}

A partir de junio de 2020 estamos realizando, por encargo del doctor Manuel Palma Ramírez, presidente decano de la Facultad de Teología San Isidoro de Sevilla, el inventario de todos los Fondos documentales heredados por dicha Facultad ${ }^{56}$ : Centro de Estudios Teológicos (1969-2019), Escuela diocesana de Teología para Seglares (19681014) e Instituto Superior de Ciencias Religiosas San Isidoro y San Leandro de Sevilla (2011----) con las siguientes Escuelas diocesanas: Catequesis San Isidoro, Liturgia San Isidoro, Hermandades y Cofradías San Fernando, Familia y Vida María Reina de la Familia, Formación para la Acción Caritativa y Social Caritas Christi y Medios de Comunicación Beato Marcelo Spínola. Todas estas instituciones académicas reciben y generan documentación. Hemos creido conveniente, después de hablar con nuestra amiga e investigadora, Isabel González Ferrín ${ }^{57}$, también miembro de la Cátedra "Beato Marcelo

56 Agradezco a mi antiguo alumno Manuel Palma Ramírez, actual presidente decano de la Facultad de Teología San Isidoro de Sevilla, este gesto de confianza. Para un historiador es un privilegio confeccionar el inventario de un archivo. Y más para mi. He sido alumno del Centro de Estudios Teológicos (1969-1971) y profesor del mismo (1986-2019) y de la Escuela diocesana de Teología para Seglares (1987-2003). Ambas instituciones académicas forman parte de mi vida personal e intelectual. Desde estas páginas, mi más sincero agradecimiento al doctor Manuel Palma, amigo y compañero del claustro de profesores de la Facultad de Teología San Isidoro de Sevilla, de la que soy profesor invitado, impartiendo la asignatura de la historia de la Iglesia moderna.

57 Conozco a Isabel González Ferrín desde 1992 al incorporarse para trabajar en el Archivo de la Catedral de Sevilla. En 1995 pasó como jefa de Área del Archivo General del Arzobispado de Sevilla. A partir de dicha fecha, además de sus servicios como archivera, hemos participado en congresos de la Asociación de Archiveros de la Iglesia en España y en publicaciones conjuntas. En 1998 publicó, juntamente con nuestro común amigo Pedro Rubió Merino, director del archivo dicesano y del catedralicio, el segundo volumen del "Inventario General del Archivo de la Santa Metropolitana y Patriarcal Iglesia Catedral de Sevilla". Desde 2008 formamos parte de la Cátedra "Beato Marcelo Spínola", organizando, con los demás miembros de la misma, un ciclo de conferencias todos los años y la publicación del Anuario de Historia de la Iglesia Andaluza hasta el día de hoy. Siempre he contado con su ayuda, sobre todo cuando he necesitado de sus conocimientos y saber. A ella debemos el cuadro de clasificación del Fondo documental de la Escuela diocesana de Teología para Seglares. Desde estas páginas mi público reconocimiento y agradecimiento 
Spínola" y jefa de Área de Archivos de la Institución Colombina de Sevilla, respetar el principio de procedencia de cada Fondo. Por ello, después de todos estos consejos, hemos seguido el criterio de considerarlos fondos incorporados al de la Facultad de Teología San Isidoro de Sevilla y, como es obvio, los que cuentan con mayor antigüedad y volumen documental son el histórico del Centro de Estudios Teológicos de Sevilla (1969-2019) y el de la Escuela diocesana de Teología para Seglares (1968-2014).

Actualmente estamos realizando el inventario de estos dos últimos fondos documentales. Hemos finalizado el de la Escuela diocesana de Teología para Seglares y se encuentra en estado muy avanzado el del Centro de Estudios Teológicos. El de la Escuela diocesana es pequeño en volumen y reproduce las tipologías documentales de todo centro educativo, entre las que podemos encontrar las secciones de Gobierno, Gestión Académica y Organización de la Docencia, Administración y Varios, así como las series de correspondencia, programas de las asignaturas y de los seminarios impartidos, libros de actas académicas o calificaciones, expedientes académicos, convalidaciones de asignaturas, diplomas, certificados de estudios, Asociación de Antiguos Alumnos "San Telmo", libros de cajas y cuentas corrientes y administración ${ }^{58}$. También hay que subrayar que en el Fondo del Centro de Estudios Teológicos encontramos mucha documentación de la Escuela diocesana de Teología para Seglares, ya que ambas instituciones académicas, aunque independientes en la dirección y economía, compartieron los mismos edificios: palacio de San Telmo, instalaciones prefabricadas (las llamadas "caracolas") en los jardines del palacio y a partir del curso 1999-2000 en la zona académica del nuevo edificio del seminario matropolitano de Nuestra Señora del Buen Aire y San Isidoro, situado en la avenida Bueno Monreal, 43, donde sigue hasta el día de hoy. Y lo más importante, más del ochenta por ciento del profesorado era el mismo. En esta primera fase ofrecemos, por tanto, el cuadro de clasificación y el inventario del Fondo documental de la Escuela diocesana de Teología para Seglares, integrado en el Archivo de la Facultad de Teología San Isidoro de Sevilla.

por su ayuda y amistad. Sin sus orientaciones y correciones no hubiera sido posible la organización de este Fondo.

58 RUBIO MERINO, P. Archivística Eclesiástica. Nociones básicas (Sevilla 1999) 141-143. 


\section{1. Cuadro de clasificación}

\begin{tabular}{|l|}
\hline \multicolumn{1}{c|}{ Fondo Documental: } \\
ESCUELA DIOCESANA DE TEOLOGÍA PARA SEGLARES (1968 -2014) \\
\hline Sección I. GOBIERNO \\
\hline I.1. Serie: Correspondencia $(1985-2013)$ \\
\hline Cajas 1 y 2 \\
\hline
\end{tabular}

\begin{tabular}{|l|}
\hline Sección II. Gestión Académica y Organización de la Docencia \\
\hline Serie: II.1. Programas de las Asignaturas (1968-2014) \\
\hline Cajas 1,2, 3 y 4 \\
\hline Serie: II.2. Cursos de Actualización / Seminarios (1990-2007) \\
\hline Cajas 1, 2, y 3 \\
\hline Serie: II.3. Fichas de Alumnos (1975-2014) \\
\hline Cajas 1 a la 18 \\
\hline Serie: II.4. Convalidaciones (1968-2001) \\
\hline Caja 1 \\
\hline Serie: II.5. Expedientes Académicos (1968-2014) \\
\hline - Primeros (1968-1992) \\
\hline Carpetas 1,2,3, y 4 \\
\hline - Segundos (1992-2014) \\
\hline Cajas 1 a la 8 \\
\hline Serie: II.6. Libros de Actas de Calificaciones Académicas (1968-2014) \\
\hline Cajas 1 a la 8 y una carpeta \\
\hline Serie: II.7. Certificados de Estudios (1983-2006) \\
\hline Caja 1 \\
\hline Serie: II.8. Diplomas (1969-2014) \\
\hline Caja 1, Libro 1 y Carpeta 1 \\
\hline
\end{tabular}

\begin{tabular}{|l|}
\hline Sección III. Administración \\
\hline Serie: III.1. Libros de Ingresos y Gastos (1986-2010) \\
\hline Libros 1 al 5 \\
\hline Serie: III.2. Justificantes de Pagos (1987-2012) \\
\hline Cajas 1 y 2 \\
\hline
\end{tabular}

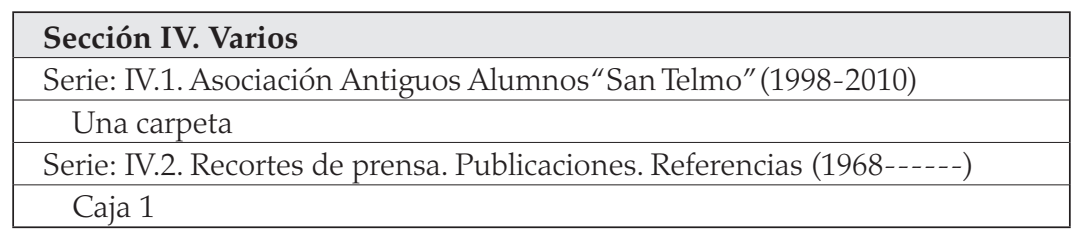




\section{2. Inventario CORRESPONDENCIA (1985 a 2013)}

Caja 1 (10 febrero 1987 al 13 mayo 2013): esta caja contiene la documentación y cartas recibidas en dicho periodo. Entre ellas figuran: invitaciones a conferencias, defensas de tesis doctorales, presentaciones de libros, actos litúrgicos de la catedral, etc.; hojas del semanario de la Iglesia de Sevilla (2008, 2009, 2010, 2011 y 2012); dípticos de facultades de teología; jornadas teológicas del Centro de Estudios Teológicos (CET); invitación al acto de la imposición de la medalla de oro del CET al cardenal AmigoVallejo (1 octubre 2010) y a Jesús Colombo Roquette, profesor del CET y de la Escuela (1 diciembre 2010 a título póstumo); cartas de profesores; cartas de alumnos de la Escuela y de otras instituciones académicas; invitaciones de la Asociación de Antiguos Alumnos "San Telmo" (marzo 2007); ayuda a Cáritas (15 enero 2007); cartas del cardenal Amigo Vallejo.

Caja 2 (25 octubre 1985 al 2 mayo 2013): cartas de José María Estudillo Carmona y de Antonio Bueno Ávila, como directores de la Escuela, al arzobispo, alumnos, familias, profesores de la Escuela, asociación de "San Telmo", párrocos y hermanos mayores de las hermanadades sobre cursos de actualización teológica; claustro de profesores; actos institucionales (entre ellos el homenaje al profesorado el 13 de febrero de 2008); jornadas teológicas del CET; cartas de los secretarios de la Escuela; seminarios ofrecidos; cursos de actualización teológica; cambios de horarios; convocatorias de misas celebradas por profesores y alumnos difuntos; calendarios académicos; celebraciones eucarísticas en determinados momentos (comienzo de curso, adviento, navidades, miércoles de ceniza, final del curso académico); entrega de diplomas; homenaje a Carlos Amigo por su designación al cardenalato; homenaje a Miguel Oliver, cofundador y profesor de la Escuela; programa de actualización teológica (enero, febrero y marzo de 2006); fechas de exámenes; cuestionarios de revisión de los cursos de actualización teológica y propuestas de otros cursos; entrega de colecta a Cáritas; homenajes a tres profesores veteranos: Miguel Oliver Román, José María Garrido Luceño y Juan Guillén Torralba; acta-resumen de la reunión del profesorado del 10 de noviembre de 1999 sobre el modelo de evaluación del alumnado; invitación a la asistencia a las jornadas teológicas del CET; información 
de José María Estudillo sobre la posibilidad de crear en Sevilla un centro superior de ciencias de la religión (12 febrero 1996). Desde junio de 1985 a octubre de 1989 esta caja 2 recoge la correpondencia cursada y recibida. Entre ellas: cartas del director a los alumnos de la Escuela; entrega de diploma a la promoción 1993-94 (25 mayo 1995); comunicados a los profesores; cartas de alumnos al director de la Escuela; invitaciones a la celebración de los 25 años de la creación de la Escuela; (primera semana de reflexión teológica (noviembre 1993); presentación de la revista sobre la Escuela (18 mayo 1994); jornada de convivencia para los antiguos alumnos (mayo 1994); celebración de la misa de Félix Amo, bibliotecario de la Escuela (3 febrero 1989 en la capilla del seminario).

\section{PROGRAMAS DE LAS ASIGNATURAS (1968-69 al 2013-14)}

Caja 1: Programas (1968 al 2011): esta caja contiene todo tipo de documentación: guía de la Escuela diocesana de Teología para Seglares (1970); recortes de periódicos (1972-1974); curso diocesano de teología (1968-69); programa información sobre la Escuela (196970, 1971-72, 1972-73); muchos dípticos y tripticos de propaganda y de información sobre la Escuela: materias, matrículas, profesorado, alumnado, calendarios, actividades, etc. (1968-1995); memoria del curso académico 1993-94; balance del curso de la Escuela diocesana de Teología para Seglares (hoja diocesana del 21 de julio de 1996); VI jornadas teológicas del CET (10 al 12 de marzo de 1997); normas de régimen interno (1991-92); agendas académicas (1996-97, 1997-98, 1999-2000, 2000-01, 2001-02, 2002-03, 2003-04, 2004-05, 2005-06, 2006-07, 2007-08, 2008-09, 2009-10 y 2010-11); IX jornadas teológicas del CET (20 al 22 de marzo de 2000); XVIII jornadas teológicas del CET (2-4 de marzo de 2009).

\section{Caja 2: Programas (1997-98 al 2007-08):}

Primer curso (1995 al 2008): introducción al misterio de Dios (2007-08: José María Alcober); introducción al nuevo testamento (2000-01, 2002-03, 2003-04, 2004-05, 2005-06, 2006-07 y 2007-08: María Dolores Ruiz); liturgia fundamental (2007-08: Luis Rueda Gómez); teología fundamental (2007-08: Antonio Bueno Ávila); (Juan Guillén Torralba, sin fecha); teología fundamental (2004-05: 
Enrique Aguiló Bonín); el Dios de la revelación. Introducción al misterio de Dios (1995, 2001-02 y 2005-06: José Miguel Núñez Moreno); pentateuco y libros históricos (2000-01: Manuel Castro Román); pentateuco y libros históricos (2003-04: Miguel Ángel Garzón). La casi totalidad de los programas contiene una amplia bibliografía.

Segundo curso (2006-07 al 2007-08): doctrina social de la Iglesia (Jesús Duque, sin fecha); el hombre nuevo. Antropología teológica (José María Garrido Luceño, sin fecha); el Jesús de los evangelios y el evangelio de Jesús (Miguel de Burgos, sin fecha); doctrina social de la Iglesia (2006-07: Manuel Palma Ramírez); doctrina social de la Iglesia (2007-08: Mariano Pérez de Ayala Conradi); introducción a la doctrina social de la Iglesia (Roberto Miralles Seguí, sin fecha); la iniciación cristiana (Luis Fernando Álvarez González, sin fecha); historia de la Iglesia antigua y medieval (José Antonio González Sáinz de la Maza, sin fecha); el sacramento del orden (Antero Pascual Rodríguez, sin fecha); el evangelio de Jesús (Miguel de Burgos, sin fecha); teología del matrimonio (solamente el programa); sacramentos de la iniciación cristiana (Francisco J. Rodríguez Fassio, sin fecha). La casi totalidad de los programas contiene una amplia bibliografía.

Tercer curso (1996-97 al 2007-08): teología fundamental (Jesús Colombo Roqueette, sin fecha); eclesiología (1998-99, 2000-01, 200203 y 2004-05: Rosa Carbonell de la Fuente); la salvación desde la historia de las grandes religiones (2003-04, 2004-05 y 2007-08: José María Estudillo); cristología (Fernando Camacho, sin fecha); moral fundamental y personal (1996-97: Jesús Colombo Roquette). La casi totalidad de los programas contiene una amplia bibliografía.

Cuarto curso (1997-98 al 2007-08): reconciliación y penitencia (solamente el programa); historia de la Iglesia moderna y contemporánea (2003-04, 2005-06 y 2007-08: José Luis García de la Mata Calvo); libros proféticos (Miguel Ángel Garzón, sin fecha); el apóstol Pablo en la historia del cristianismo primitivo (Manuel Mallofret, sin fecha); sacramento de la unción de los enfermos (1997-98: Francisco de Llanos Peña y Amalia Rodríguez Bernal); teología del laicado (José Morales Carmona, sin fecha); teología del laicado (Ignacio Gaztelu Pastor, sin fecha); historia de la Iglesia moderna y contemporánea (1997-98, 2000-01 y 2002-03: Manuel Martín Riego); escatología 
(solamente el programa). La casi totalidad de los programas contiene una amplia bibliografía.

\section{Caja 3: Programas (2008-09 al 2013-14):}

Primer curso (2008-09 al 2010-11): teología fundamental (Antonio Bueno Ávila, sin fecha); profetas y profetismo, los libros sapienciales y cómo leer un texto bíblico (Gonzalo Flor Serrano, sin fecha); pentateuco y libros históricos (2008-09 y 2009-10: Miguel Ángel Âlvarez Paulino); introducción al misterio de Dios (2010-11: José María Alcober Brenchat); introducción al nuevo testamento (2010-11: María Dolores Ruiz Pérez); liturgia fundamental (Luis Rueda Gómez, sin fecha). Todos los programas contieneen una amplia bibliografía.

Segundo curso (2008-2011): historia de la Iglesia antigua y medieval (2008-09, 2009-10, 2010-11 y 2011-12: José Luis García de la Mata Calvo); el hombre nuevo. Antropología teológica (José María Garrido Luceño, sin fecha); doctrina social de la Iglesia (2009-10, 2010-11 y 2011-12: Mariano Pérez de Ayala Conradi); sacramento del orden (Antero Pascual Rodríguez, sin fecha); teología del matrimonio (Francisco Javier Fernández de Liencres, sin fecha); 1 Corintios: una ventana con miras a la vida de los primeros cristianos (201011: Álvaro Pereira Delgado con la colaboración de Manuel Mallofret Lancha); evangelios sinópticos (Álvaro Pereira Delgado, sin fecha); la iniciación cristiana (Luis Fernando Álvarez González, sin fecha, y otra sin profesor ni fecha); mariología (Álvaro Román Villalón, sin fecha). Casi todos los programas contienen una amplia o breve bibliografía.

Tercer curso (2008-09 al 2012-13): Jesús de Nazaret (Fernando Camacho, sin fecha); moral fundamental (solamente el programa); Lucas y Hechos (2010-11: Antonio Guerra Martínez); eclesiología (Ángel Sánchez Solís, sin fecha); la salvación desde la historia de las grandes religiones. Camino y praxis del actual diálogo interreligioso (2008-09, 2009-10, 2010-11, 2011-12 y 2012-13: José María Estudillo Carmona). Todos los programas contienen una amplia bibliografía.

Cuarto curso (2008-09 al 2013-14): el apóstol Pablo en la historia del cristianismo primitivo (Manuel Mallofret Lancha, sin fecha); 
libros proféticos (Miguel Ángel Garzón Moreno, sin fecha); historia de la Iglesia moderna y contemporánea (2008-09, 2009-10, 2010-11, 2012-13 y 2013-14: José Luis García de la Mata Calvo); sacramento de la unción y pastoral de la salud (Francisco de Llanos Peña y Amalia Rodríguez Bernal , sin fecha); los laicos: su misión en la Iglesia y en el mundo (2008-09, 2009-10, 2010-11 y 2012-13, no consta el profesor); reconciliación y penitencia (Manuel Cotrino Bautista, sin fecha); escatología (2013-14: María Dolores Ruiz Pérez). Todos los programas contienen una amplia bibliografía.

\section{Caja 4: Programas (1991-92 al 2007-08):}

Primer Curso (1991-92 al 2008-07): pentatateuco y libros históricos (2006-07: Miguel Ángel Álvarez Paulino); pentatateuco y libros históricos (Manuel Castro Román, sin fecha); formación del antiguo testamento (Gonzalo Flor, sin fecha); el Dios de la revelación. Introducción al misterio de Dios (2001-02: José Miguel Núñez Moreno); el Dios de la revelación. Introducción al misterio de Dios (2006-07: José María Estudillo); teología fundamental (1995-96, 2001-02 y 2002-03: Enrique Aguiló Bonín); iniciación a la celebración cristiana (1993-94, 1997-98 y 1999-2000: Luis Fernando Álvarez); introducción al nuevo testamento (1993-94 y 1995-96): Miguel Oliver; evaluación de introducción al antiguo testamento (junio 1994: Miguel Oliver); temas de antiguo testamento (1992-93: Juan Guillén); el misterio de María en la reflexión de la Iglesia (1992-93: Antonio Calero); introducción al nuevo testamento (1991-92 y 199293: Jaime Andrade Bermudo).

Segundo Curso (1991-92 al 2002-03): historia de la Iglesia antigua y medieval (José Antonio González Sáinz de la Maza, sin fecha); teología del matrimonio (1997-98, 2001-02 y 2002-03: Fernández de Liencres); doctrina social de la Iglesia (Roberto Miralles, sin fecha); bautismo y confirmación (José Morales Carmona, sin fecha); antropología teológica (solamente el programa); sacramentos de la iniciación cristiana (Rodríguez Fassio, sin fecha); el compromiso de la vida cristiana (José María Garrido Luceño, sin fecha); relación de temas monográficos (solamente el programa); iniciación a la celebración (1992-93 y 1997-98: Luis Fernando Álvarez); doctrina social de la Iglesia (1993-94: Jesús Duque); el sacramento del Orden (1991-92: Antero Pascual); evangelio de Jesús (Miguel de Burgos, sin fecha); 
sacramentos de la iniciación cristiana (Valentín Vigueras, sin fecha); el Espíritu en la obra de Lucas (Miguel de Burgos, sin fecha).

Tercer Curso (1991-92 al 2007-08): eclesiología (1991-92: Francisco Martín); eclesiología (1996-97: Antonio Calero); eclesiología (Rosa Carbonell, sin fecha); eclesiología (2007-08: Ángel Sánchez Solís); la salvación desde la historia de las religiones -programa, texto, guías didácticas y evaluación- (2004-05, 2006-07 y 2007-08: José María Estudillo Carmona); cristología (Fernando Camacho, sin fecha); teología moral fundamental y personal (1994-95 y 1997-98: Jesús Colombo); María en el misterio de Dios y de la Iglesia (solamente el programa).

Cuarto Curso (1990-91 al 2007-08): libros proféticos (2007-08: Miguel Ángel Garzón); teología del laicado (Ignacio Gaztelu Pastor, sin fecha); penitencia (Francisco Martín, sin fecha); reconciliación y penitencia (1997-98, no figura el profesor); historia de la Iglesia moderna y contemporánea (1990-91, 1992-93 y 2001-02: Martín Riego); historia de la Iglesia moderna y contemporánea (2006-07: José Luis García de la Mata Calvo); sacramento de la unción y pastoral de la salud (1999-2000 y 2000-01: Francisco de Llanos y Amalia Rodríguez Bernal); temas proféticos (1994-95 y 1999-2000: Juan Guillén); escatología (Pedro León, sin fecha); el apóstol Pablo en la historia del cristianismo primitivo (1997-98: Manuel Mallofret Lancha ); los Hechos de los Apóstoles y Pablo (Manuel Mallofret Lancha, sin fecha); teología del laicado (Antonio Calero, sin fecha).

Seminarios (1991-92): se conserva en esta caja la relación de los seminarios impartidos en el curso académico 1991-92. Solamente contiene el programa del seminario de Jaime Andrade. La documentación conserva los nombres de los seminarios, profesores y las fechas en las que se impartieron:"la comunidad de Jesús desde el evangelio" (Fernando Camacho, 5 noviembre a 17 diciembre 1991);"religiosidad popular y evangelización" (José María Estudillo, 6 noviembre a 18 diciembre 1991);" oración y vida cristiana" (Jaime Andrade Bermudo, 9 enero a 5 marzo 1992); "realidades temporales y compromiso cristiano" (José Robles y equipo); "mariología" (Antonio Calero, 5 mayo a 2 junio 1992). 


\section{SEMINARIOS (1990 a 2007)}

Caja 1 (1990-91 al 1996-97): cada seminario contiene las fichas de los alumnos. Son 8 seminarios en este periodo: "Cristología" (1996-97). No figura el director y son 106 alumnos, de los que 85 son mujeres; "Hombre nuevo. Mandamiento nuevo" (1995-96). Lo imparten los profesores: Fernando Camacho, Manuel Mallofret, José María Estudillo, Miguel de Burgos, Jesús Colombo y Enrique Aguiló. Son 85 alumnos, de los que 63 son mujeres; "Oración y liberación" (1994-95). Lo imparte Francisco Martín Rodríguez. Son 41 alumnos, de los que 33 son mujeres; "Reinado de Dios" (1993-94). Lo imparte Fernando Camacho y asisten 38 alumnos, de los que 34 son mujeres; "Mariología" (1992-93). Lo imparte Antonio Calero y asisten 35 alumnos, de los que 27 son mujeres; "Las bienaventuranzas" (199293). Lo imparte Jaime Andrade y asisten 56 alumnos, de los que 46 son mujeres; seminario (1991-92). No figura ni el título ni el director. Son 36 alumnos, de los que 31 son mujeres; "Religiosidad popular" (1990-91). Lo imparte José María Estudillo. Son 16 alumnos, de los que 10 son mujeres.

Caja 2 (1997-98 al 2000-01): Cada seminario contiene la temática, profesores y relación de los alumnos. Son siete seminarios: "La oración. Una dimensión existencial de cristiano" (2000-01). Se trata de un seminario para los antiguos alumnos de la Escuela. Los profesores: Juan Guillén, Gonzalo Flor, Miguel de Burgos, Manuel Mallofret, Miguel F. de Haro Iglesias, Rosa Carbonell y José María Garrido. Alumnos: 115, de los que 89 son mujeres; “La salvación en el 2000, año jubilar" (1999-2000). Ponentes: Juan Guillén, Fernando Camacho, Manuel Mallofret, Miguel de Burgos, Manuel Martín Riego y José María Garrido Luceño. Alumnos: 51, de los que 39 son mujeres; “Dios Padre" (1998-99). Ponentes: José María Garrido Luceño, María Pablo Romero, Juan Gullén y Alfonso García Araya. Alumnos: 73, de los que 48 son mujeres; “El Espíritu: Señor y dador de vida para el mundo y la comunidad" (1997-98). Ponentes: Juan Guillén, Luis Fernando Ávarez González, José María Garrido Luceño, Miguel de Burgos y Manuel Mallofret; "Jesucristo: clave de la historia y centro de la comunidad cristiana" (1996-97). Ponentes: Juan Guillén, Gonzalo Flor, Fernando Camacho, Antonio Calero, Jesús Colombo, José María Garrido y José María Estudillo; "Hombre Nuevo. Mandamiento Nuevo" (1995-96). 
Ponentes: Fernando Camacho, Manuel Mallofret, José María Estudillo, Miguel de Burgos, Jesús Colombo y Enrique Aguiló. Contiene los esquemas de las ponencias y las oraciones relacionadas con cada ponencia; "Oración y liberación" (1994-95). Contiene el programa. Son 83 alumnos, de los que 68 son mujeres.

Caja 3 (2001-02 al 2006-07): "La salvación de Dios es universal" (2001-02). Ponentes: Gonzalo Flor, Juan Guillén, Manuel Mallofret, María Dolores Ruiz, José María Estudillo y José María Garrido.Alumnos: 46, de los que 28 son mujeres; "Comunidad humana, comunidad cristiana" (2002-03). Figuran los títulos de las ponencias, 7 en total (del 16 de enero al 6 de marzo de 2003, pero no aparecen los ponentes. Son 43 alumnos, de los que 30 son mujeres; "Resurrección: plenitud de la vida tras la muerte" (2003-04). Ponentes: Miguel de Burgos, José María Estudillo, Manuel Mallofret, Pedro León, José María Garrido Luceño y Gonzalo Flor Serrano. Alumnos: 91, de los que 72 son mujeres; “Retos actuales: propuesta cristiana" (2004-05). Ponentes: Miguel de Burgos, Luis Fernando Álvarez, Anonio Calero, José María Estudillo, Jesús Colombo, Manuel Mallofret y José María Garrido Luceño. Contiene la caja varios esquemas de las ponencias. Alumnos: 53 alumnos, de los que 31 son mujeres; “Esta es nuestra esperanza: la existencia cristiana en tiempos difíciles" (2005-06). Ponentes: Manuel Martín Riego, Miguel de Burgos, Gonzalo Flor, José María Estudillo, Roberto Miralles, Manuel Mallofret y José María Garrido Luceño. Contiene varios esquemas de las ponencias. Alumnos: 93, de los que 67 son mujeres; "La Biblia, libro de la comunidad". No figuran ni los títulos de las ponencias ni los ponentes. Alumnos: 48, de los que 37 son mujeres.

\section{FICHAS DE ALUMNOS (1975-76 al 1994-95)}

Una sección importante es la que conserva las fichas de todos los alumnos matriculados. Tenemos un total de 18 cajas con los alumnos matriculados desde el curso académico 1975-6 al 1994-95. En las fichas aparecen todos los alumnos tanto si estaban matriculados en cursos completos como en asignaturas sueltas.

Caja 1 (1975-76 al 1976-77): Alumnos de primero y segundo de teología. 
Caja 2 (1977-78 al 1978-79): Alumnos de primero y segundo de teología.

Caja 3 (1979-80 al 1980-81): Alumnos de primero, segundo y tercero de teología. En esta caja las fichas de matrículas incluyen las respuestas de los alumnos al siguiente cuestionario: medios por los que ha conocido esta Escuela de Teología; qué le ha decidido matricularse; problemas del mundo o de la Iglesia que más le preocupa; lo que espera y le gustaría encontrar por medio de los profesores, materias, compañeros, etc. Aquí podemos encontrar una gran gama de respuestas, aunque todos subrayan la necesidad de una mayor formación religiosa tanto personal como para ayudar en sus parroquias o movimientos apostólicos.

Caja 4 (1981-82): Alumnos de primero, segundo y tercero de teología. Esta caja contiene también las respuestas al mismo tipo de cuestionario que la caja n. 3 .

Caja 5 (1982-83): Alumnos de primero, segundo y tercero de teología. En esta caja enontramos las respuestas a dicho cuestionario solamente por parte de los alumnos de primero.

Caja 6 (1983-84): Alumnos de primero, segundo y tercero de teología.

Caja 7: (1984-85): Alumnos de primero, segundo y tercero de teología.

Caja 8 (1985-86): Alumnos de primero, segundo, tercero y cuarto de teología.

Caja 9 (1986-87): Alumnos de primero, segundo, tercero y cuarto de teología.

Caja 10 (1987-88): Alumnos de primero, segundo, tercero y cuarto de teología.

Caja 11 (1988-89): Alumnos de primero, segundo, tercero y cuarto de teología. 
Caja 12 (1989-90): Alumnos de primero, segundo, tercero y cuarto de teología.

Caja 13 (1990-91): Alumnos de primero, segundo, tercero y cuarto de teología.

Caja 14 (1991-92): Alumnos de primero, segundo, tercero y cuarto de teología.

Caja 15 (1992-93): Alumnos de primero, segundo, tercero y cuarto de teología.

Caja 16 (1993-94): Alumnos de primero y segundo. Por primera vez aparece en el reverso de la ficha las asignaturas de cada uno de los cuatro cursos de teología. Es el único curso académico con dos cajas: una para primero y segundo y la otra para tercero y cuarto de teología.

Caja 17 (1993-94): Alumnos de tercero y cuarto. Las fichas contienen la relación de las asignaturas de cada uno de los cuatro cursos de teología.

Caja 18 (1994-95): Alumnos de primero, segundo, tercero y cuarto de teología.

\section{EXPEDIENTES ACADÉMICOS (1968-2014)}

Estas carpetas contienen las fichas de los alumnos matriculados, juntamente con sus respectivas calificaciones académicas. Para los expedientes antiguos tenemos 4 cajas para los cursos comprendidos entre 1968-69 y 1991-92. En estos expedientes son muy pocos los que reflejan las notas del cuarto curso de teología. En el siguiente cuadro ofrecemos las letras con las que comienzan y finalizan las cajas. Hemos calificado a estos expedientes como antiguos. 


\section{EXPEDIENTES ACADÉMICOS ANTIGUOS (1968-1992)}

\begin{tabular}{|c|c|l|l|}
\hline Caja & Letras & Primera ficha & Última ficha \\
\hline 1 & A/D & Abdín Orozco, Eduardo & Durán Sánchez, Josefa \\
\hline 2 & E/J & Embuena Romero, Agustín & Jurado González, Isabel \\
\hline 3 & L/Q & Lara Sánchez, Rosa María & Quiles Mancilla, Josefa \\
\hline 4 & R/Z & Ramos Borges, Francisco Javier & Zulategui Azagra, Asunción \\
\hline
\end{tabular}

A partir del curso 1992-93 al 2013-14 los expedientes se guardan en 8 cajas verdes, siendo la documentación más completa. Cada ficha de alumno contiene los siguientes datos: nombre y apellidos, domicilio, teléfono de contacto, edad, estado civil, profesión, estudios, estado eclesiástico (sacerdote-religioso-seglar) y observaciones. Cada ficha tiene su foto tipo carnet y la fecha de la obtención del diploma, si lo obtuvo. En el reverso de este documento aparecen las notas de cada una de las asignaturas de los cuatro cursos, si es que se examinó, y el abono de las tasas de las matrículas. En el siguiente cuadro ofrecemos la relación de las 8 cajas de los expedientes académicos de las alumnos matriculados entre 1992 y 2014.

\section{EXPEDIENTES ACADÉMICOS (1992-2014)}

\begin{tabular}{|c|c|l|l|}
\hline Caja & Letras & Primera ficha & Última ficha \\
\hline 1 & A/B & Abad Luque, Carmen & Busto Cano, Ignacio \\
\hline 2 & C/E & Caballero Barrón, Domingo & Espinosa Quiñones, Yaccenia \\
\hline 3 & F/G & Fabián Moreno. Manuel & Guzmán Molina, Dolores \\
\hline 4 & H/L & Halcón Álvarez, Angustias & Luque Rojas, Ana María \\
\hline 5 & $\mathrm{M}$ & Macaya Floristán, Josefa & Mutva Pauline, Kakini \\
\hline 6 & N/Q & Naranjo González, Salvador & Quintanilla Quesada, Encarnación \\
\hline 7 & $\mathrm{R}$ & Rabadán Bujalance, Salud & Rupérez Alfonso, Amparo \\
\hline 8 & $\mathrm{~S} / \mathrm{Z}$ & Sanz Azcárate, María Teresa & Zuazo Malaxetxebar, Nerea \\
\hline
\end{tabular}

CONVALIDACIONES (1968-2001)

Caja 1 (1968-2001): en todo archivo de estudios superiores suele haber un fondo dedicado a las convalidaciones. Todas las comprendidas en esta caja son con centros de estudios teológicos, universidades 
y escuelas de magisterio de la Iglesia, delegaciones de enseñanza de obispados, etc. En esta caja aparecen los certificados de estudios expedidos por los siguientes centros de estudios de la Iglesia de cara a las posibles convalidaciones. Mencionamos los siguientes: CEDISET del arzobispado de Oviedo; Instituto de Liturgia"San Isidoro"del arzobispado de Sevilla; Facultad de Teología de Granada; Instituto Superior de Pastoral de la Universidad Pontificia de Salamanca; Escuela diocesana de Teología de Mondoñedo-Ferrol; Universidad de Deusto; Centro de Estudios Catequéticos de Sevilla; Cursos Bíblicos a distancia (PPC-Madrid); Escuela de Formación Teológico-Catequética "Regina Apostolorum" de Madrid; Instituto Teológico Femenino "Santa Teresa" de Granada; Instituto de Estudios Teológicos"Nuestra Señora del Pilar de Zaragoza"; Pontificio Instituto "Regina Virginum" de Madrid, centro agregado al Pontificio Instituto "Regina Mundi" de Roma; Instituto de Teología de Barcelona; Escuela Universitaria de Formación del Profesorado de E.G.B. de Málaga; Centre D’Estudis diocesà de Gerona; Centro diocesano de Teología de Málaga; Centro de Estudios Teológicos de Sevilla; Instituto Teológico“LuxVera” de La Coruña; Comisión Nacional de Estudios de Teología y Catequética de los Hermanos de las Escuelas Cristianas; Instituto Social León XIII de la Universidad Pontificia de Salamanca; Instituto diocesano "Madre de la Iglesia" de Cádiz; Instituto Femenino de Ciencias Sagradas "Santa María" de Valladolid; Centro Nacional de la Iglesia para la Orientación y Promoción de la Educación Cristiana (CENIEC) de Madrid; Escuela de Teología de la Universidad de Sevilla; Centro de Estudios de Vida Religiosa"Mater Ecclesiae" de Madrid.

\section{LIBROS DE ACTAS DE CALIFICACIONES (1968-2014)}

Como es obvio, una sección muy importante del archivo de un centro académico son los libros de actas de calificaciones. Sin ellos no tendrían validez los estudios realizados Esta sección contiene 8 cajas que reflejan las calificaciones de los alumnos matriulados desde el curso 1968-69 a 2013-14. De la lectura de esta documentación mencionamos los siguientes aspectos: en los primeros cursos la Escuela diocesana de Teología no tenía sello propio y aparece con el del Instituto de Orientación Pastoral del Arzobispado de Sevilla; también en los primeros años las actas reflejan el nombre de las asignaturas, pero no el del profesor; el gran predominio de las religiosas en 
los primeros años; se mantiene durante los 46 años de la Escuela el elevado número de mujeres; en los primeros cursos académicos son muchos los alumnos que no se examinan, asistiendo simplemente para formarse; posteriormente aumenta el número de los que se examinan; a partir de la caja 2 ya aparece en cada acta el profesor de cada asignatura; A partir del curso 1992-93 las actas aparecen firmadas, normalmente, por el profesor, el secretario y el director, contando ya la Escuela con su propio sello.

A partir de la caja 7 aumentan los alumnos que no quieren calificaciones, cosa lógica, ya que la Congregación para la Educación Católica, con fecha de 13 de noviembre de 2011, festividad de San Leandro, firmó el decreto de erección del Intituto Superior de Ciencias Religiosas San Isidoro y San Leandro. A partir de esta fecha, como ya hemos indicado en más de una ocasión, la Escuela diocesana de Teología para Seglares, se irá extinguiendo progresivamente. De aquí que la caja 8 sea reflejo de esta progresiva desaparición. En el curso académico 2013-14 solamente aparecen los alumnos de cuarto, ya que primero, segundo y tercero habían desaparecido. En el siguiente cuadro ofrecemos las fechas de inicio y de finalización de cada una de las cajas.

\section{LIBROS DE ACTAS DE CALIFICACIONES (1968/69 al 2013/14)}

\begin{tabular}{|c|l|}
\hline Cajas & Fecha \\
\hline 1 & $1968 / 69 \mathrm{al} 1979 / 80$ \\
\hline 2 & $1980 / 81 \mathrm{al} 1988 / 89$ \\
\hline 3 & $1989 / 90 \mathrm{al} 1993 / 94$ \\
\hline 4 & $1994 / 95 \mathrm{al} 1997 / 98$ \\
\hline 5 & $1998 / 99 \mathrm{al} 2000 / 01$ \\
\hline 6 & $2001 / 02 \mathrm{al} 2005 / 06$ \\
\hline 7 & $2006 / 07 \mathrm{al} 2009 / 10$ \\
\hline 8 & $2010 / 11 \mathrm{al} 2013 / 14$ \\
\hline
\end{tabular}

Tenemos también una carpeta con Actas: curso 1968/69 al curso 1975/76 con primero y segundo de teología. 


\section{CERTIFICADOS DE ESTUDIOS (1983-2006)}

Caja 1 (1983 a 2006): esta caja contiene los certificados de estudios expedidos por la Escuela diocesana de Teología para Seglares desde 1983 a 2006. Dichos certificados van acompañados de las calificaciones de cada una de las asignaturas. La mayor parte de ellos están firmados por José Sánchez Moreno, secretario de la Escuela, (2 por Justo Pérez Alcántara, secretario y seminarista en el curso 19841985) y desde noviembre de 1991 al 23 de marzo de 2006 por José María Estudillo Carmona, director de la Escuela. También contiene la caja, apetición de los interesados, certificados justificativos de estar matriculados, horarios de clase y asistencia a exámenes.

\section{DIPLOMAS (1969-2014)}

Caja 1: Diplomas (1969/70 al 2013/14): esta caja contiene la relación de todos los alumnos y alumnas que obtuvieron diploma de haber realizado todos los cursos en la Escuela diocesana de Teología para Seglares desde el curso 1969/70 al 2013/14. Dicho documento aparece firmado por el arzobispo, el rector del Centro de Estudios Teológicos de Sevilla y el director de la Escuela. En los primeros años predominan los diplomas de las religiosas y religiosos, aunque de estos últimos no se indica el estado civil ${ }^{59}$.

\section{Libro de Diplomas (1969-2014)}

Se trata de un libro donde aparece la relación de todos los alumnos que obtuvieron el diploma de haber cursado todos los estudios. Solamente contiene los nombres y el año académico. El libro tiene 21 páginas escritas con anverso y reverso con un total de

59 Fondo documental de la Escuela Diocesana de Teología para Seglares. Sección II: Gestión Académica y Organización de la Docencia-Diploma, caja n. 1. Llegamos a esta conclusión a partir de la lectura de determinada documentación y por mi conocimiento de algunos de ellos. Tenemos cinco cartas de religiosas autorizando a una persona para que recoger títulos de hermanas destinadas en Roma o en otro lugares de España. También una carta de fray Antonio Enríquez Guerrero, ministro de la provincia bética de los franciscanos, autorizando a un religioso a recoger el diploma de fray José Luis Sánchez Tercero, que se encontraba destinado en el convento de San Antonio de Cáceres. 
1.225 alumnos diplomados. Predominan los títulos de las religiosas en los primeros años y las mujeres sobre los hombres.

\section{Carpeta de Diplomas no recogidos por los Alumnos (1986-7/2014)}

En el archivo se conserva una carpeta con 44 diplomas no recogidos por los propios alumnos: el primero es el número 445, de 15 de octubre de 1986, firmado por Carlos Amigo Vallejo, arzobispo de Sevilla, y el último el número 1.221, firmado en 2017 por Juan José Asenjo Pelegrina, arzobispo de Sevilla.

\section{ASOCIACIÓN DE ANTIGUOS ALUMNOS (1998-2010)}

Carpeta 1 (1998-2010): se trata de una carpeta tamaño cuartilla que contiene todas las fichas de los miembros de la Asociación de Antiguos Alumnos "San Telmo", de la Escuela diocesana de Teología para Seglares. Cada ficha contiene los siguientes datos: apellidos, nombre, DNI, foto, domicilio, teléfono, fecha de alta, promoción y cuenta bancaria. Los primeros socios son del 6 de febrero de 1998 diciembre y los últimos de noviembre de 2004. La mayor parte de ellos se hicieron socios en el curso académico 1999-2000. Hay dos tipos de socios: fundadores y numerarios.

\section{ADMINISTRACIÓN (1986-2012)}

Libro 1: Cuentas corrientes (5 septiembre 1986 al 30 junio 1992): este libro contiene las cuentas de la Escuela diocesana de Teología para Seglares con un total de 35 páginas escritas dobles (anverso y reverso). Lo comienza el 5 de septiembre de 1986 José Sánchez Moreno, secretario de la Escuela, y lo finaliza el mismo secretario el 30 de junio de 1992. Este primer libro de cuentas corrientes contiene todas las anotaciones de ingresos y gastos del periodo indicado. Entre los ingresos figuran: matrículas y certificados. Y entre los gastos: sellos, materiales de oficina, fotocopias, hononarios del director, secretario, biliotecario, porteros, profesores y personal de limpieza, regalos a conferenciantes, diplomas, libros, revistas, guía diocesana, hoja diocesana, propaganda, agenda académica, dípticos y trípticos informativos, teléfono, megafonía, comida del profesorado y empleados (navidad y final del curso académico), reparaciones y cantidades 
pagadas a la administración del seminario por el uso del edificio. Esta aportación al seminario por el uso de edificio lo hacían todas las instituciones ubicadas en el palacio de San Telmo: Centro de Estudios Teológicos, Escuela Universitaria de Formación del Profesorado de EGB (1972-1994), Escuela de Monitores y Residencia Universitaria.

Libro 2: Cuentas (17 septiembre 1990 al 30 juio 1992): este segundo libro contiene la relación de entradas y salidas de la fecha indicada. Repite lo anotado en la caja anterior en dicha fecha. Son un total de 37 páginas dobles y una solo por el anverso (pag. 38). Han sido anotadas por el secretario José Sánchez Moreno.

Libro 3: Cuentas (16 septiembre 1992 al 26 junio 1996): este tercer libro de cuentas refleja las entradas y salidas económicas de la Escuela en el periodo indicado. Son 95 páginas dobles y una por el anverso (pag. 96). Los ingresos siguen siendo por las matrículas y los certificados académicos, donativos del 25 aniversario de la Escuela, venta de la revista de la celebración de los 25 años.Y las salidas: gratificación de del personal docente o de servicio (director, secretarios, profesores, bibliotecario, portero del seminario y personal de limpieza). A estas salidas hay que añadir: obsequios a conferenciantes, material de oficina e informática, suscripción a la revista Isidorianum, diplomas, imprenta Sand, comida de convivencia, aportación al seminario y culto (flores y velas).

Libro 4: Cuentas (3 septiembre 1997 al 26 junio 2002): este cuarto libro de cuentas refleja las entradas y salidas económicas de la Escuela en el periodo indicado. Entre las entradas tenemos las siguientes: matrículas de cursos y seminarios, certificados y expedientes. Y entre los gastos: material informático y de oficina, gratificaciones del director, secretarios, profesores, limpieza y portero, propaganda, campaña de navidad de Cáritas, fotocopias, imprenta Sand, teléfono, bebidas en celebraciones y en las entregas de diplomas, revista Isidorianum, agenda académica, abono al CET (150.000 pesetas en el curso 1997/98), devoluciones de matrículas, donativo a Cáritas y fiesta de fin de curso. Hay que recordar que, a partir de enero de 2002, las cantidades de ingresos y gastos aparecen en euros. En el curso académico 2001-02 los ingresos de la Escuela ascendieron a $38.618^{\prime} 85$ euros y los gastos a 36.637'55 euros. 
Libro 5: Cuentas (1 agosto 1995 al 25 junio 2002): se trata de una libreta tipo cuartilla que recoge cuentas sueltas de determinadas épocas (1-8-1995 al 20-12-1995; 1-1-1996 al 18-12-1996; 8-1-1997 al 12-12-1997; 7-1-1998 al 18-12-1998; 12-1-1999 al 21-12-1999; 11-12000 al 20-12-2000; 9-1-2001 al 20-12-2001; 8-1-2002 al 25-6-2002 (fol. 1-48). En los folios 51 y 52 hay un apartado que dice"Saldo en Arzobispado". Interpretamos que desde el 8 de noviembre de 2000, coincidiendo con la ubicación de la Escuela en el nuevo edificio del seminario metropolitano, el dinero se colocó en la administración del arzobispado, ingresando lo recibido en la Escuela por matrículas y otros ingresos y sacando para los gastos de siempre. En el fol. 125 hay varios movimientos (50.000 pesetas entregadas a Cáritas, 80.000 pesetas gastadas en la comida de final del curso académico 1999/2000 y 180.000 para gastos imprevistos). Quedó a nombre de la Escuela la cantidad de 1.331.286 pesetas, las mismas que el 5 de noviembre de 2000 se entregaron en la administración del arzobispado como fondo de la Escuela diocesana de Teología para Seglares.

Caja 1: Administración (15 septiembre 1987 a enero 1991): esta caja contiene una relación de todas las anotaciones de gastos desde las fechas indicadas. La letra es del secretarario, José Sánchez Morenos. Entre los gastos figuran los siguientes: gratificaciones de profesores y personal auxiliar (director, secretario y bibliotecario), imprenta, fotocopias, teléfono, efectos de correos, materiales de oficina, muebles, revistas y libros, magafonía, celebraciones, gratificaciones, servicios y materiales de limpieza, aportación para el mantenimiento del edificio y aportación para matrículas gratuitas de alumnos con menos medios económicos. También contiene el presupuesto económico del curso 1990-91. Ascienden los ingresos a 1.987 .000 pesetas (1.673.000 en concepto de matrículas y 314.000 por asignaturas sueltas). Los gastos ascienden a 2.386 .881 pesetas (2.320.381 en gastos generales y las 66.500 pesetas restantes de matrículas gratuitas). El curso finaliza con un déficit de 399.881 pesetas.

Caja 2: Administración (2003-04 al 2011-12): esta caja contiene varios portafolios y sobres con las cuentas de los siguientes cursos académicos: 2001-02, 2003-04, 2005-06, 2006-07, 2007-08, 2009-10, 2010-11 y 2011-12. La documentación refleja los ingresos y gastos de estos cursos académicos. Entre los gastos figura la aportación al 
Centro de Estudios Teológicos para el mantenimiento del edificio: 10.292 '17 euros cada año. El informe menciona la relación de profesores y el desglose general de los conceptos de entradas y salidas. Los informes económicos suelen aparecer con la firma del administrador del arzobispado y las director y del secretario de la Escuela. La casi totalidad de los balances son deficitarios para la Escuela.

La rendición de cuenta del curso 2007-08 incluye el presupuesto del curso académico 2008-09 y una relación de profesores con sus titulaciones, cargo pastoral y asignaturas impartidas en la Escuela. El informe del curso 2009-10 contiene una breve memoria del curso académico y las cuentas. También un desglase por profesiones de los 210 alumnos matriculados. La rendición de cuentas del curso académico 2010-11 incluye una breve memoria de dicho curso y al final una estadística de los alumnos matriculados, un total de 218, especificando sus profesiones, edades medias, sexo y estado. Por último, esta caja contiene el presupuesto económico del curso académico 2011-12 y el balance de gastos, un total de 19.800 euros. El balance aparece firmado por el director y el secretario de la Escuela y por la administración general del arzobispado.

\section{VARIOS (1968-2014)}

Carpeta 1 (1998-2010): se trata de una carpeta tamaño cuartilla que contiene todas las fichas de los miembros de la Asociación de Antiguos Alumnos "San Telmo", de la Escuela diocesana de Teología para Seglares. Cada ficha contiene los siguientes datos: apellidos, nombre, DNI, foto, domicilio, teléfono, fecha de alta, promoción y cuenta bancaria. Los primeros socios son del 6 de febrero de 1998 diciembre y los últimos de noviembre de 2004. La mayor parte de ellos se hicieron socios en el curso académico 1999-2000. Hay dos tipos de socios: fundadores y numerarios. Como es natural, por las matriculaciones predominan las mujeres. La casi totalidad de los socios son de la ciudad de Sevilla y pueblos cercanos (Gines, Mairena del Aljarafe, Tomares, Pilas, Aznalcázar, Santiponce, Villamanrique, La Rinconada, Coria del Río, Carmona, Dos Hermanas, Brenes, etc.). Algunos de pueblos más lejanos: El Garrobo, Marchena, Fuentes de Andalucía, Morón, Écija, Moguer (Huelva), etc.

Caja 1 (1968-2014): será una caja que, una vez revisado el Fondo documental de Escuela y trabajado el del Centro de Estudios 
Teológicos, la completaremos. Hasta ahora contiene: recortes de prensa, agendas académicas, propaganda, revista del 25 aniversario de la Escuela (1968-1994). De esta institución académica tenemos muchas referencias en el Fondo documental del Centro de Estudios Teológicos de Sevilla. Esperamos poder incluir muchas de ellas en el Fondo documental de la Escuela. En ello estamos trabajando actualmente. También incluiremos este primer acercamiento a la historia y al Fondo documental de la Escuela diocesana de Teología para Seglares cuando esté publicado en el volumen XIV del Anuario de Historia de la Iglesia Andaluza. 